\title{
Santo Domingo, entre la historia y la tradición hagiográfica castellana (siglos XIII-XVI)
}

\author{
Saint Dominic, between history and the Castilian \\ hagiographic tradition (13th-16th centuries)
}

\section{Guillermo NIEVA OCAMPO}

Facultad de Humanidades CEPIHA Universidad Nacional de Salta / CONICET https://orcid.org/ooo-0001-9610-7264 nievaocampoguillermo@gmail.com

\begin{abstract}
In this paper, the current knowledge we have about the life of Santo Domingo is presented in a synthetic way, founder of the Order of Preachers, and the sources with which his hagiography had been constructed throughout the 13th century are analysed. From there, the additions and aspects that the 16th century chroniclers highlighted about the life of the saint are examined, educated in the ideals of regular observance and in humanistic criticism, who, precisely, proposed the founder as the model of the observant Castilian friar. In fact, the chronicles of the Order must be considered as stories proper, but, above all, as writings of religious formation for the friars themselves.
\end{abstract}

Keywords: Saint Dominic; Dominicans; Chronicles and chroniclers; Observances; 15th and 16th centuries.
Resumen: En el presente artículo, se expone en modo sintético el conocimiento actual que tenemos sobre la vida de Santo Domingo, fundador de la Orden de Predicadores, y se analizan las fuentes con las que se había construido su hagiografía a lo largo del siglo XIII. A partir de ello, se examinan los agregados y aspectos que destacaron sobre la vida del santo los cronistas del siglo XVI, formados en los ideales de la regular observancia y en la crítica humanística, quienes, justamente, proponían al fundador como el modelo del fraile castellano observante. De hecho, las crónicas de la Orden deben ser consideradas como historias propiamente dichas, pero, sobre todo, como escritos de formación religiosa para los mismos frailes.

Palabras clave: Santo Domingo; Dominicos; Crónicas y cronistas; Observancias; siglos XV y XVI.

Han sido numerosas las publicaciones y las reuniones científicas que en las dos últimas décadas se han dedicado al santo fundador de la Orden de los Frailes Predicadores y a los orígenes de la misma, coincidiendo con sendos aniversarios en la historia de los dominicos. Estas han permitido actualizar los resultados ya 
obtenidos por los estudios de Hubert-Marie Vicaire ${ }^{1}$, Pierre Mandonnet ${ }^{2}$ y Simon Tugwel ${ }^{3}$.

Sin querer ser reiterativo, propongo a continuación un breve perfil biográfico de Santo Domingo a la luz de esos avances, para poder revisar, a continuación, la construcción que realizaron de su figura los cronistas que se habrían formado, estudiado y ejercido su docencia en conventos observantes de Castilla, entre finales del siglo XV y durante el siglo XVI. Si tal como señala Gabriela Zarri, las reformas observantes comportaron una verdadera refundación de las órdenes religiosas surgidas en el Medioevo, los cronistas formados en sus ideales se afanaron por cubrir las necesidades identitarias de esas renovadas comunidades de frailes, adaptando, introduciendo o enfatizando aspectos de la hagiografía del fundador hasta entonces soslayados, en un contexto paradójicamente caracterizado por una notable labor de crítica documental, producto de su propia formación humanista ${ }^{4}$.

\section{SANTO DOMINGO SEGÚN LA HISTORIOGRAFÍA ACTUAL}

Domingo habría nacido en Caleruega, una villa castellana sin mayor relevancia, entre los años 1170 y 1174. Pedro Ferrando, quien escribió sobre el santo fundador hacia 1240, señala que sus padres se llamaban Félix y Juana. Si bien la hagiografía medieval atribuye comúnmente un origen noble a los santos y santas, no parece ser el caso de Domingo ${ }^{5}$. En la Castilla del siglo XII, los miembros más pudientes de la comunidad adquirían un caballo y las armas adecuadas para combatir y, gracias a su participación en las campañas militares, desempeñaban cargos concejiles e ingresaban en la nobleza como caballeros. Sin embargo, las características sociales del padre de Domingo aportadas por Ro-

1 Hubert-Marie VICAIRE, Historia de Santo Domingo, Madrid, 2003 [1 $1^{\text {a }}$ ed. en francés: 1982].

2 Pierre Mandonnet, Saint Dominique. L'idée, l'bomme, l'œuvre, Paris, 1938, 2 vols.

3 Simon Tugwell, Notes on the life of St. Dominic, en Archivum Fratrum Praedicatorum, 65 (1995), pp. 5-169; 66 (1996), pp. 56-141; 67 (1997), pp. 27-59; 68 (1998), 5-116; 73 (2003), pp. 5-141.

4 Gabriella ZARRI, Ecclesiastical Institutions and Religious Life in the Observant Century, en James MiXsOn y Bert Roest (ed.), A Companion to Observant Reform in the Late Middle Ages and Beyond, Leiden y Boston 2015, pp. 23-59.

5 Una tradición elaborada por los cronistas del siglo XIII que es recogida por Vicaire, considera a Domingo como un personaje linajudo, descendiente de dos poderosas estirpes, los Guzmán y los Aza. Véase, Hubert-Marie VICAIRE, Historia de Santo Domingo, Madrid, 2003, pp. 82-88. 
drigo de Cerrato en su Vitae Sanctorum, escrita hacia 1260, no parecen coincidir con este perfil social ${ }^{6}$.

Domingo fue educado durante su infancia por sus padres y, a partir de los 7 años, por un magister pariente suyo, es decir, por un clérigo. Era tradición que algunos clérigos acogiesen en sus casas a jóvenes aprendices a cambio de algún dinero pagado por los padres o de trabajos manuales, lo que no requería que sus progenitores fuesen particularmente ricos.

A partir de los 13 años, Domingo habría continuado su formación en el Studium generale de Palencia ${ }^{7}$. Para sufragar su educación, el joven recibió una canonjía en la catedral de Osma. De hecho, hacia 1195 figura como suprior del cabildo catedralicio. Se puede suponer que el beneficio que le fue dado a Domingo en Osma tenía como fin el que estudiara derecho en Palencia y pusiera después sus talentos al servicio de la catedral. Pero, según Jordán de Sajonia, Domingo, que se interesaba mucho más por el trabajo pastoral -recuérdese el episodio de la venta de sus libros para asistir a los pobres de Palencia durante la gran hambruna- se orientó, finalmente, hacia la teología.

Para ese momento, el capítulo de Osma había sido reformado por el obispo Martín de Bazán como comunidad de canónigos regulares en base a la Regla de San Agustín ${ }^{8}$. Los canónigos regulares eran una orden híbrida de monjes clérigos, surgida en el transcurso del siglo XI como respuesta a la propaganda de reforma que alentaba al clero secular a vivir en comunidad en base al modelo de la primera vida apostólica9 ${ }^{9}$ Las casas de clérigos regulares seguían una amplia variedad de observancias, pero todos sus códigos preveían un régimen monástico basado en la renuncia de la propiedad personal y una vida comunitaria con un refectorio y

6 Lorenzo Galmes y Vito T. GómEZ, Santo Domingo de Guzmán. Fuentes para su conocimiento, Madrid, 1987, p. 338. Adeline Rucquoi discute los resultados obtenidos por Anthony Lappin, que quiere ver en los padres de Domingo a individuos pertenecientes a una anacrónica «clase media». Véase, Adeline RuCQuoI, Dominicus Hispanus: ochocientos años de la Orden de Predicadores, Junta de Castilla y León, Valladolid, 2016, p. 39; Anthony LAPPIN, On the family and early years of Saint Dominic of Caleruega, en Archivum Fratrum Praedicatorum, 67 (1997), pp. 5-26.

7 Adeline RUCQUOI, La double vie de l'université de Palencia (c.1180-c.1250), en Studia Gratiana, XXIX (1998), pp. 723-748.

8 Lázaro SASTRE VARAS, El obispo Diego de Acebes y el Cabildo de la catedral de Osma. Raíces espirituales de Santo domingo de Guzmán, en Domenico di Caleruega e la nascita dell'Ordine dei Frati Predicatori. Atti del XLI Convegno storico internazionale. Todi, 10-12 ottobre 2004, Espoleto, 2005, pp. 106-117; Juan Loperráez Corvalán, Descripción histórica del obispado de Osma, t. III, nº XXIII, p. 46 y $\mathrm{n}^{\circ} \mathrm{XXIV}$, pp. 46-47.

9 Cliffort H. LAWRENCE, Medieval Monasticism: Forms of Religious Life in Western Europe in the Middle Ages, New York, 1984, pp. 148-156 [existe edición en español]. 
dormitorios comunes, organizados alrededor de la exigencia de cantar el oficio divino de las horas canónicas.

Diego de Acebes sucedió a Martín de Bazán en 1201. Había sido prior del cabildo oxomense en 1195 cuando Domingo era suprior. Mantenía, como la mayor parte de los prelados, una estrecha relación con el rey Alfonso VIII, que lo envió a Dinamarca a buscar esposa para su hijo Fernando ${ }^{10}$. La tradición recuerda que «visitava su obispado a pie, y muchas vezes descalço, mostrando con sus hechos el bien publico que desseava a los suyos» ${ }^{11}$.

Fue en el verano de 1203, durante la misión diplomática a la corte de Dinamarca, que Domingo conoció directamente la fuerza de la herejía cátara en la sociedad del Languedoc ${ }^{12}$. Pasando la noche en Toulouse quedó sorprendido cuando descubrió que un inquilino de la posada era miembro de dicha secta y se quedó despierto toda la noche discutiendo con él. La tarea de combatir la herejía en el Midi francés había sido encargada por el papa a los cistercienses bajo la dirección de Arnaud-Amaury, abad de Cîteaux; pero la misión oficial había obtenido pocos resultados contra los sectarios, quienes estaban bien organizados y gozaban del apoyo de la aristocracia local. En 1206, durante el viaje de regreso de una segunda expedición a la corte danesa, Diego y Domingo se dirigieron a Roma, puesto que el obispo solicitó a Inocencio III que aceptara la renuncia a su diócesis para dedicarse a la predicación misional entre los cumanos, pero el papa los envió al Languedoc para que auxiliaran a los misioneros cistercienses. Encontraron a los legados papales en Montpellier y después de haber escuchado la narración de su fracaso decidieron emprender también ellos la tarea.

A este punto, Jordán de Sajonia -sucesor de Domingo como maestre de la Orden y su primer biógrafo- reporta una significativa conversación entre los dos grupos de misionarios. Diego sostenía que los abades cistercienses eran obstáculos por su estilo prelaticio y su amplio séquito: «Yo pienso que tu no deberías proceder de esta manera. Puedes ver como los herejes presentan una apariencia de santidad, y fingiendo de ser un ejemplo de pobreza y austeridad evangélica, convencen a las personas simples que acepten sus sistemas». Solo los simples se-

10 Lázaro SaStre VARas, El obispo Diego de Acebes... [ver n. 8], pp. 117-121.

11 Gil GONZÁlez DávILA, Teatro eclesiástico de la Iglesia y Ciudad de Osma, Salamanca, 1618, pp. 2930.

12 Martín Alvira Cabrer, Muret 1213. La batalla decisiva de la Cruzada contra los Cátaros, Barcelona, 2008, pp. 11-52; Raoul MANSELLI, Eglises et théologies cathares, en Cabiers de Fanjeaux, 3 (1993), pp. $129-176$. 
guidores de la vida apostólica podían esperar de asegurarse un auditorio como auténticos predicadores del Evangelio. Era el problema de competir con los «perfectos», la elite espiritual de la secta cátara, famosos por su austeridad personal y por la renuncia a los bienes mundanos.

La vida apostólica, en el significado dado a ella durante los cincuenta años precedentes, significaba la vida de un predicador itinerante que había renunciado a la propiedad personal y dependía de las limosnas para comida y vestimentas ${ }^{13}$. Este era el modelo que Diego sugería a sus colegas clérigos. Los dos españoles convencieron a los abades cistercienses para sumarse a ellos. El obispo dio un buen ejemplo mandando a casa a los servidores y clérigos junto con los caballos. Paso seguido, el grupo comenzó andando a pie un viaje itinerante de predicación, teniendo discusiones públicas con los líderes de los cátaros a Servian y Béziers y en otras ciudades del Midi francés ${ }^{14}$. Era simplemente la aplicación práctica de la noción de vida apostólica madurada durante el siglo XII, una vida dedicada a la predicación evangélica y a la pobreza voluntaria ${ }^{15}$.

Durante el invierno de 1206-07, Diego dispuso la fundación del monasterio femenino de Prouille, cercano a Fanjeaux, un renombrado centro disidente. Prouille era una alternativa a los asilos abiertos por los cátaros y a la ausencia de

13 «Solamente all'inizio del XIII secolo, e specialmente a partire dal Concilio Lateranense IV del 1215 , la Chiesa iniziò a provvedere attivamente alla cura pastorale e alla predicazione, sia per colmare la precedente lacuna, sia soprattutto come risposta alle crescenti eresie che costituivano una minaccia all'autorità della Chiesa cattolica in varie aree d'Europa. Presieduto da papa Inocenzo III, il Concilio, uno dei più riformatori nella storia della Chiesa, emanò nuove linee di condotta per la predicazione, determinando in questo modo la posizione ufficiale nei confronti della sua natura e della sua importanza. Il suo scopo principale fu quello di assicurare più predicazione a carico di un clero ben preparato», Cornelia LINDE, Frati Predicatore e predicazione dalle origini alla fine del XVI secolo, en Gianni FeSTA y Marco RAININI (ed.), L'Ordine dei Predicatori. I Domenicani: storia, figure e istituzioni (1216-2016), Roma, 2016, pp. 257-277 [259].

14 Sobre la actividad pastoral de Diego de Aceves y su grupo de predicadores entre los cátaros del Midi véase, Lorenzo PaOlini, Domenico e gli eretici, en Domenico di Caleruega e la nascita dell'Ordine dei Frati Predicatori... [ver n. 8], pp. 297-326.

15 « Dès le 17 novembre 1206, Innocent III avalise la prédication dans la pauvreté radicale ; il demande à son légat de déléguer toute autorité à ceux que la mettent en œuvre. Le mode d'action des missionnaires réside dans l'ascèse apostolique et dans la prédication, mais aussi dans la controverse [...] Ces confrontations produisent quelques résultats. Des vaudois, à Pamiers, se rallient à l'Église et forment le mouvement des Pauvres catholiques. Surtout, les prédicateurs ramènent à l'orthodoxie un certain nombre d'adhérent des bons hommes. Quelques femmes, en 1246-47, déclarent devant les inquisiteurs avoir été réconciliées jadis avec l'Église par saint Dominique », Jean Louis BIGET, Saint Dominique, la société du Languedoc, les bons hommes et les vaudois (1206-1217), en Domenico di Caleruega e la nascita dell'Ordine dei Frati Predicatori... [ver n. 8], pp. 131-179 [133-134]. 
monasterios femeninos en la región ${ }^{16}$. A continuación, el obispo volvió a Castilla con el fin de obtener recursos para la construcción de la reciente fundación, pero allí encontró la muerte. Entonces, Domingo tuvo que partir a Castilla y sólo pudo regresar al Midi recién en $1211^{17}$. De este modo, pudo continuar con su ministerio pastoral y promover el desarrollo de la comunidad de Prouille en los tristes años de la cruzada contra los albigenses dirigida por Simón de Montfort.

Pero fue en Tolosa donde se estableció con sus primeros compañeros. La fundación fue posible gracias al decidido apoyo del obispo Fulco, quien en 1215 donó a Domingo algunas casas en Tolosa, donde el santo fundó un emplazamiento para la hermandad de predicadores, y también les concedió una parte de las décimas de la diócesis. De este modo, podían disponer de una renta regular para sostener su actividad. A diferencia de Francisco de Asís, Domingo buscó desde el comienzo crear una hermandad de clérigos cultos, que tuvieran la formación necesaria para una misión especial de predicación.

El obispo Fulco vio en Domingo la posibilidad de salvar la poca ortodoxia que había quedado en su diócesis. En el otoño de 1215 decidió que se debía dar un status oficial a la nueva institución y llevó consigo a Domingo en dirección a Roma para solicitar a Inocencio III la autorización para la fundación de una nueva orden de predicadores y para confirmar las donaciones. Los dos fueron recibidos gentilmente por la Curia y obtuvieron sin dificultad los documentos que confirmaban la propiedad de Prouille. Sin embargo, en relación con la propuesta de crear una orden de religiosos con la tarea de predicar, el papa hizo esperar su respuesta. La predicación y la concesión de licencias para predicar eran ex professo funciones propias de los obispos. Atribuir estas prerrogativas a una comunidad monástica parecía una anomalía, sobre todo teniendo en cuenta que la ley canónica excluía a los monjes del ministerio en las iglesias públicas.

16 Se trataba de «un grupo anche cospicuo di sorores, o domine, come in alcuni atti privati esse vengono definite, che erano guidate e si avvalevano, per quanto riguarda le esigenze pastorali, ma anche di gestione economica, di una piccola comunità di fratelli. Il gruppo, la cui struttura istituzionale appare comunque, nei primi decenni del Duecento, piuttosto fluttuante, era guidato nel suo complesso da un priore - il primo di cui è rimasta traccia è Natale nel 1216 - e da una priora, attestata già nel 1207. Centrale rimase la posizione di Domenico [...] In sintesi, il monastaro di Santa Maria di Prulle, fondato da Diego di Osma, ma ben presto affidato alle cure dei suoi due discepoli, Domenico di Caleruega e Guglielmo di Claret, rappresentò per almeno un decennio l'unico riferimento istituzionale del piccolo gruppo di predicatore». Guido CARIBONI, Domenico e la vita religiosa femenina, en Domenico di Caleruega e la nascita dell'Ordine dei Frati Predicatori... [ver n. 8], pp. 327-360 [332-333].

17 Simon Tugwel, Schéma chronologique de la vie de Saint Dominique, en Domenico di Caleruega e la nascita dell'Ordine dei Frati Predicatori... [ver n. 8], pp. 1-24 [7-8]. 
En el momento en que Domingo presentó su petición, los prelados de la Cristiandad se estaban reuniendo para celebrar el cuarto concilio lateranense -el más grande y el más famoso de los concilios medievales- durante el cual uno de los términos en discusión fue justamente la reglamentación de las órdenes religiosas. En el intento por contener aquello que parecía un campo de experimentación, los padres conciliares decretaron que, a causa de la multiplicidad y de la confusión, nadie más podía crear ordenes nuevas. A cualquiera que deseara fundar una nueva fraternidad se le solicitaba adoptar una regla monástica ya existente y aprobada. Debiendo enfrentarse a este inesperado cambio de planes, Domingo regresó para discutir la situación con sus congregados de Tolosa. La solución que adoptaron fue la más obvia: ampararse bajo la Regla de san Agustín, a la cual Domingo estaba ya vinculado por ser un canónigo regular ${ }^{18}$.

La Regla de san Agustín, en su forma mitigada y difundida a finales del siglo XII, derivaba de la carta 211 de Agustín, originalmente dirigida a una comunidad de monjas. Uno de sus aspectos más curiosos era la generalidad: el todo se reducía casi solamente a un discurso sobe la castidad, la pobreza, la caridad y la concordia, destinado a aquellos que deseaban abrazar la vida de una comunidad religiosa. Pocas indicaciones eran ofrecidas sobre cómo organizar un monasterio u ordenar una jornada monástica. Así, adoptándola para su hermandad, Domingo fue libre de programar la organización y las observancias de sus predicadores como mejor lo consideraba. La confirmación papal, obtenida de Honorio III en 1216, era una autorización vaga que no hacía más que reconocer la existencia de la fraternidad y confirmar sus posesiones en Tolosa. El privilegio Religiosam vitam no ratificaba ninguna regla especifica parangonable a la de los franciscanos. Se organizaron capítulos generales que dieron a la Orden su extraordinaria constitución, la cual no fue jamás confirmada por el papado, cosa que tampoco se buscaba obtener ${ }^{19}$. Oficialmente, la Orden de los Predicadores era simplemente una rama de los canónigos regulares.

18 Maria Pia Alberzoni, I nuovi Ordini, il IV concilio lateranense e i Mendicanti, en Domenico di Caleruega e la nascita dell'Ordine dei Frati Predicatori... [ver n. 8], pp. 39-89 [72-84].

19 «The transition from canons to preachers, from a society to a religious order, required twenty years' time to work out, minimally from 1216 to 1236 . And was not fully operational until well into the 1240s. It became ever more substantive in expression, first in the customary/constitutions of 1239/41 and then especially in acts of the general chapter in the years 1249-51, thirty years along. This only provoked efforts, supported by the pope, top write a whole new rule that would codify what the order has become. This was stopped by Humbert and the general chapter in the mid-1250s, and thereafter the legislative process gained its own momentum. But this generation of steady transition, of participatory inventiveness, importantly for the life and spirit 
Hasta ese momento, la hermandad de Tolosa había confinado su actividad de predicación a la provincia de Narbona. Una cuestión favorecida por las buenas relaciones con los líderes cruzados, en particular con Simón de Montfort. De hecho, Domingo celebró el matrimonio de su hijo, Amauri, en 1214, y recibió el castillo de Casseneuil y diversos bienes con destino a la comunidad de Prouille. Por otro lado, la comunidad de predicadores también se asociaba con el mundo urbano no noble, al recibir a sus miembros entre sus filas, que para su formación seguían un curso de teología en la catedral de Tolosa. Por lo tanto, los predicadores de Domingo, siguiendo la idea de Diego de Acebes, habían nacido para responder a la necesidad de dar una ayuda al clero languedosiano en su lucha contra los cátaros. Eran predicadores diocesanos, que debían desarrollar su actividad pastoral en pobreza evangélica ad extirpandam eretica pravitatem et vitia expelenda et fidei regulam edocendam et hominem sanis moribus imbuendo.

Pero, durante el verano de 1217, Domingo anunció a los hermanos su decisión de enviarlos en una misión universal de predicación. De este modo, se produjo una notable mutación en los objetivos y constitución de la primera comunidad religiosa. Inocencio III había excomulgado al conde Raimundo VI de Tolosa y, si bien este último se había reconciliado con la Iglesia practicando una penitencia pública, el Concilio de Letrán ratificó la expropiación de sus territorios. Desde el verano de 1215 , Raimundo VI se preparaba para recuperar sus posesiones perdidas con la ayuda de un ejército formado en Aragón. Tolosa estaba por convertirse en el epicentro de una nueva guerra. Tradicionalmente, se ha pensado que frente a esta amenaza Domingo había decidido alejar de la región a todos los hermanos, a excepción de un pequeño grupo, provocando la diáspora de la comunidad de Tolosa. Sin embargo, hoy sabemos que en el proyecto de dispersión existía en realidad un programa de expansión de la Orden promovido por el cardenal obispo de Ostia, Hugo dei Conti di Segni, futuro Gregorio IX, a quien Domingo había conocido durante la reunión del concilio lateranense ${ }^{20}$.

of the order, itself became incorporated into their constitutions, marked by three crucial points placed in the very introduction. Creative tension between rule and ongoing legislative power was transformed into a matter of abiding principle. As from the beginning, now also in their constitutions and constitution-making, the mission priors could dispense from the constitutions, diffinitors could over-rule priors and depose master generals, and general chapters could make all necessary laws, further interpreting the rule. Though only after three years of deliberations». John Van Engen, From Canons to Preachers: A Revolution in Medieval Governance, en Domenico di Caleruega e la nascita dell'Ordine dei Frati Predicatori... [ver n. 8], pp. 261-295 [295].

20 «Cardinal Hugolinus had been a long-time supporter of the friars. By the time Honorius died in 1227 . Hugolinus probably almost 60 years old. Her was a member of the extended family of 
Domingo permaneció en Roma hasta el mes de febrero de 1217. Rainini destaca que el castellano frecuentó durante esas semanas la domus del cardenal Hugo dei Conti di Segni, que era pariente de Inocencio III $^{21}$. Allí conoció a algunos personajes que tendrían una parte relevante, cuanto no central, en la historia de su religio. Se trataba de Guglielmo di Monferrato, que se convirtió en fraile predicador y, según él, en principalis socius de Domingo. También entró en contacto con otro Guglielmo, futuro obispo de Módena y luego cardenal, que tendría un importante protagonismo en los sucesos que llevarán a la canonización del castellano. Con gran probabilidad fue por mediación del cardenal Hugo que Domingo conoció un año después a Reginaldo de Orleáns, un destacado maestro de París, que se convirtió luego en prior del convento de Bolonia y, posteriormente, de París. Se trata de un personaje que adquirió una gran relevancia entre los primeros frailes.

Entre los demás personajes del entorno del cardenal que serían importantes en el desarrollo de la Orden, vale la pena señalar a Giuseppe, monje de San Giovanni in Fiore, el monasterio fundado por Joaquín de Fiore, ex cisterciense con fama de profeta. Giuseppe era un agente de confianza de Hugo -dado el interés por la profecía y la escatología que tenía el cardenal de Ostia- y estuvo al lado de Domingo pocos años después, en mayo de 1220, para la organización de una campaña de predicación en el norte del Italia que recordaba a las campañas desarrolladas por Domingo y Diego de Acebes en Languedoc. Probablemente no se llevó a cabo, pero es interesante que haya sido el mismo Giuseppe, unos años después, el redactor de la carta de canonización del castellano -caracterizada por evocaciones apocalípticas-22.

Innocent III. He became the cardinal protector of the Franciscans early in Honorius pontificate. His relationship with Dominic was also close. Hugolino probably met him for the first time at the Fourth Lateran Council and afterwards in the first years of Honorius' pontificate. It is also a measure of his support for the friars that both Francis (1228) and Dominic (1234) were canonized during his pontificate. Hugolinus was elected pope as the second choice of the cardinals in March 1227. He took the name Gregory IX. He supported the friars' privileges during his pontificate». Ken Pennington, The Church from Pope Innocent III to Pope Gregory IX, en Domenico di Caleruega e la nascita dell'Ordine dei Frati Predicatori... [ver n. 8], pp. 25-38 [p. 35]. Véase también, Il papato duecentesco e gli ordini mendicanti. Atti del XXV Convegno internazionale (Assisi, 13-14 febbraio 1998), Espoleto, 1998.

21 Marco RaInINI, Domenico di Caleruega: il primo maestro dell'Ordine, en Gianni FeSTA, Marco RAININI (ed.), L'Ordine dei Predicatori... [ver n. 13], pp. 79-105.

22 Marco RAININI, I predicatori dei tempi ultimi. La rielavorazione di un tema escatologico nel costituirsi dell'identità profetica dell'Ordine domenicano, en Cristianesimo nella Storia, 23 (2002), pp. 307-343; Valeria DE FAJA, Usi politici della profezia gioachimita, en Annali dell'Istituto storio italo-germanico in Trento, 25 (1999), pp. 375-400. 
Teniendo en cuenta este contexto, es interesante que en su Vita beati Dominici, escrita a mediados del siglo XIII, Constantino de Orvieto señale como motivo de la decisión de Domingo de dispersar a los frailes en 1216, una visión que tuvo el santo en la basílica de San Pedro: los apóstoles Pedro y Pablo le habrían dado el bastón y el libro, ordenándole «Ve y predica». Justamente en Roma y bajo mandato de los dos santos cuyas divisas adornan el sello papal.

El hecho de que durante las primeras semanas de 1217 se entrevistase varias veces con el obispo de Ostia -tal como lo señala Guillermo de Monferrato- proporciona una clave para entender los movimientos y cambios que observamos, gracias a la documentación emitida por la cancillería papal y luego en las decisiones tomadas por Domingo. El 19 de enero Honorio III escribía a los maestros y estudiantes de París, invitándolos a unirse a la campaña misional de catequesis y predicación iniciada en Tolosa. El 21 de enero el papa escribe a los así llamados fratres Sancti Romani predicatoris in partibus Tolosanis: en este caso es interesante notar que la inscriptio está corregida sobre una precedente que llamaba a los frailes predicantes in partibus Tolosanis. Es decir, que en la versión definitiva se reconocía a la predicación como el oficio propio de Domingo y sus compañeros.

Tras regresar a Tolosa y en los meses sucesivos, Domingo dispuso el envío de los frailes a España, París y Bolonia. Como se ha dicho, una decisión vinculada a las conversaciones y reuniones que tuvo con los miembros de la corte romana, y no con la rebelión de Raimundo de Tolosa y el posterior asesinato de Simón de Montfort, que se produjeron recién en junio de 1217 y en septiembre de 1218, respectivamente. Esto mismo lo prueba el hecho de que Domingo volvió a Roma a principios de 1218 y que el 11 de febrero Honorio III envió una carta a los arzobispos, obispos y abades, a quienes solicita la protección de los «frailes de la Orden de los Predicadores». Se trata, por lo tanto, de un ordo con vocación universal y no solamente a la predicatio en la región de Tolosa. El 30 de marzo fue concedida a Prouille la protección apostólica y también se encargó a Domingo la reunión de todas las monjas de Roma en un solo monasterio ${ }^{23}$. Cuestión que sería realizada en 1221, nuevamente con ayuda del cardenal Hugo de Ostia ${ }^{24}$.

23 Marco RaInINI, La fondazione e i primi anni del monastero di San Sisto: Ugolino di Ostia e Domenico di Caleruega, en Gabriela ZARRI et alii (ed.), Il velo, la penna e la parola. Le domenicane: storia, instituzioni e scritture. Atti del Convegno intenazionale di studi (Bologna, 11-13 ottobre 2007), Florencia, 2009, pp. 49-70.

24 «Nell'agosto del 1218 Ugo di Ostia, allora legato papale nell'Italia centro-septentrionale, si fece rilasciare da Onorio III l'autorizzazione a dare vita a nuovi monasteri femmenili, da subito esenti dall'ordinario del luogo e soggetti al vescovo di Roma. Essi venivano in tal modo decisamente orientati verso la dimensione monastica e claustrale, segnata dall'adozione della regola di Bene- 
En mayo de 1220, en Bolonia, se había reunido el primer capítulo de la Orden, donde Domingo habría presentado su renuncia como Maestro General, que fue rechazada. Un año después, se reunió el segundo Capítulo General que delineó la primera división en provincias. Mientras tanto, Domingo se dedicó a predicar por la región del Véneto y, al finalizar, se reunió con Hugo de Ostia en Venecia. Luego regresó a Bolonia, donde murió el 6 de agosto de 1221.

Las relaciones que Domingo trabó con Hugo de Ostia y su entorno entre 1216 y 1217 afectaron enormemente el desarrollo de la Orden de Predicadores. En los siguientes años, gracias a él los frailes consiguieron iglesias en Milán, Florencia, Brescia y Bolonia, donde emplazaron sus conventos. La relación con el purpurado se extendió hasta los últimos días de la vida del santo. De hecho, el cardenal celebró su funeral y, tras ser elegido papa en 1227 con el nombre de Gregorio IX, siguió ejerciendo una gran influencia sobre la Orden.

\section{DOMINGO Y LOS PRIMEROS CRONISTAS DE LA ORDEN}

Se desconoce hasta qué punto permaneció viva la memoria del así llamado Magister et prior de la Orden de Predicadores hasta que se inició su proceso de canonización. La decisión de iniciarlo coincidió con el Alleluia de 1233, un movimiento de fervor religioso, de represión antiherética y de pacificación política de las comunas de la llanura padana dirigido por los frailes de las Órdenes Mendicantes ${ }^{25}$. Dentro de ese movimiento, en Bolonia destaca la figura de fray

detto e della forma vite per loro composta dal cardinale stesso. Nascevano così i primi monasteri 'papali' al di fuori di Roma, collocati sotto la speciale cura del cardinale Ugo, che se ne fece attivo promotore innanzi tutto nelle regioni della sua legazione, quindi, e con ancora maggior vigore, dopo la sua ascesa al soglio papale con il nome di Gregorio IX. Accanto alle iniziative per la fondazione di nuovi cenobi, la Sede Apostolica era dunque impegnata nella ricerca di colaboratore idonei per garantire la cura ai nuovi monasteri da lei promossi grazie all'iniziativa di Ugo d'Ostia», Maria Pia AlberZONI, L'Ordine dei Predicatori e la vita religiosa femmnile fino al generalato di Giordano di Sassonia, en Gianni FeSTA, Marco RAININI (ed.), L'Ordine dei Predicatori... [ver n. 13], pp. 304-324 [310].

25 « Au printemps de 1233, une onde de ferveur religieuse parcourut les régions situées entre les Apennins et les Alpes. A l'origine manifestation populaire spontanée et joyeuse, bientôt orchestrée par d'étranges personnages comme ce frère Corneto qui, sans appartenir à aucun ordre religieux, faisait chanter aux enfants de Parme des cantiques en langue vulgaire, le mouvement fit rapidement tache d'huile et s'étendit à de nombreuses cités de Lombardie. Il fut alors accaparé par les Ordres Mendiants qui surent canalise cet élan général de piété et le mettre à profit pour atteindre leurs propres objectifs [...] Lorsque les Mendiants ont obtenu le pouvoir, il l'ont exercé dans un but précis et pour une durée limitée. Leur objectif était rétablir 
Giovanni de Vicenza, quien actuaba en acuerdo con Gregorio IX, mucho más que con las autoridades de la Orden de Predicadores ${ }^{26}$. De hecho, Jordán de Sajonia, que por aquel entonces era el maestro general, se había manifestado suspicaz hacia el Alleluia, si bien las adhesiones entre los dominicos eran numerosas $^{27}$.

La predicación de Giovanni en Bolonia condujo a la «traslación» del cuerpo de Domingo, en una noche en la que se reunieron en torno a su sepulcro representantes de varios grupos que se disputaban el patronato: las autoridades municipales, el obispo y los obispos de las diócesis vecinas (entre ellos Guillermo de Módena, que había frecuentado a Domingo durante sus primeras visitas a Roma), los representantes de la Universidad y los frailes Predicadores, que con dificultad controlaron la situación ${ }^{28}$. Fray Giovanni era agente de Gregorio IX, quien canonizó un año más tarde a Santo Domingo y creó su imagen como líder de una agrupación dedicada a la cura pastoral en la célebre bula Fons Sapientae, del 3 de julio de 1234 .

Apenas canonizado Santo Domingo, la hagiografía dominica realizó un esfuerzo de (re)construcción de la memoria de una personalidad que pudiera soportar el peso del alter Christus encarnado en el fundador de los frailes Menores. Todo se había escrito sobre la personalidad de San Francisco y, por ello,

la paix en réformant la législation, car ils étaient convaincus qu'a l'origine du mal et des divisions dont souffraient les cités lombardes, se trouvaient de mauvaises lois. Une amélioration de la législation conformément aux prescriptions de l'Eglise et de la morale chrétienne devait rendre possible un bon gouvernement et rétablir un climat de concorde ». André VAUCHEZ, Une campagne de pacification en Lombardie autour de 1233. L'action politique des Ordres Mendiants d'après la réforme des statuts communaux et les accords de paix, en Mélanges d'archéologie et d'histoire, 78 (1966), pp. $503-549$ [504 y 513].

26 «Dans les événements de 1233, le rôle des Dominicains semble avoir été prépondérant. L'auteur du Chronicon Parmese a été sensible à ce fait puisqu'il appelle devotio fratrum Predicatorum le mouvement de l'Alleluia. De fait, le personnage dont l'action fit le plus de bruit sur le plan politique fut un dominicain, Jean de Vincence. D'origine 'populaire' - il était le fils d'un avocat -, il appartenait en 1233 au couvent de Bologne, qui se trouvait alors à Saint-Nicolas-des-Vignes. Dans la ville, il s'était déjà acquis un certain prestige par sa prédication, car ses thèmes favoris répondaient à l'attente des foules : il se déchaînait contre les usuriers, réclamait la libération des prisonniers pour dettes et un adoucissement de la législation dans ce domaine. Par-dessus tout, il réclamait la paix », Ibidem, p. 506. Véase también, Luigi CANETTI, Giovanni da Vincenza, en Dizzionario Biográfico degli Italiani, LVI, Roma, 2001, pp. 263-267.

27 Véase, Maria Pia AlBerzoni, Le origini dell'Ordine dei Predicatori a Milano, en Giovanni BerTUZZI (ed.), L'Origine dell'Ordine dei Predicatori e l'Università di Bologna. Atti del Convegno di Studio (Bologna, 18-20 febbraio 2005), Bolonia, 2006, pp. 194-229.

28 Marco RAInInI, Giovanni da Vicenza, Bologna e l'Ordine dei Predicatori, en Giovanni BerTUZZI (ed.), L'Origine dell'Ordine dei Predicatori... [ver n. 27], pp. 146-175. 
se trataba de mostrar que también todo estaba escrito sobre la personalidad de Domingo.

En la historia de la fundación de la Orden de los Frailes Predicadores, a diferencia de lo que había sucedido con la de los Menores, no parece haber destacado en un principio la memoria del fundador, sino, más bien, la de un conjunto de frailes y de personajes amigos que contribuyeron a ella. El título mismo del Libellus de principiis Ordinis Praedicatorum, de Jordán de Sajonia, señala que se trataba de los inicios de la Orden, más allá del caso individual de Domingo ${ }^{29}$. En realidad, esta crónica es un texto adaptado para el proceso de canonización de Santo Domingo, con algún material precedente. De hecho, el texto se configura como una hagiografía colectiva, donde, en torno al castellano, al que le es reconocido un rol central, giran otros personajes con luz propia, puesto que no eran simples reflejos del fundador.

Sin embargo, la adopción del texto de Jordán de Sajonia como Vita oficial de Santo Domingo ponía al descubierto una contradicción entre la imagen del canónico de Osma, que mostraba el Libellus, y la que ofrecía, al mismo tiempo, la documentación reunida en Tolosa y, particularmente, en Bolonia para el proceso de canonización ${ }^{30}$. Las actas boloñesas ponían en evidencia la imagen de una santidad esencialmente regular, manifestada a través del celo del fundador por la observancia, su asiduidad en la oración y las mismas exhortaciones a los frailes a respetar las prácticas regulares. Es decir, se destacaban los aspectos monásticos de la santidad de Domingo, dejando en un segundo lugar el celo apostólico o el amor a la pobreza, característicos de la vida mendicante. Según Anne Retglen Tallon, las actas del proceso representan la política oficial de la Orden en materia de construcción de la imagen del santo fundador, mucho más que el Libellus, donde se destacaba su zelus animarum, su propensión a la compasión (Domingo solía llorar por los pecadores, los infelices y los afligidos, y rezaba por su salvación) y se subordinaba su imagen como fundador a la de sus compañeros en muchos aspectos. Por otra parte, Jordán de Sajonia también había puesto en evidencia la

29 Iordani SaXonia, Libellus de principiis Ordinis Praedicatorum, Heribert Christian Scheeben (ed.), Roma, 1935. (Lorenzo GaLmES y Vito T. GómEZ, Santo Domingo de Guzmán. Fuentes para su conocimiento [ver n. 6], pp. 77-127).

30 Hay que recordar que el proceso de canonización de Santo Domingo era el primero de su tipo, que se realizaba según las nuevas normas aprobadas durante los primeros pontificados del siglo XIII. Véase, Anne TALlon, Le procès en canonisation de Saint Dominique et sa postérité dans la littérature dominicaine, en Domenico di Caleruega e la nascita dell'Ordine dei Frati Predicatori... [ver n. 8], pp. 491-510. Véase además, Lorenzo GaLmes y Vito T. GómEZ, Santo Domingo de Guzmán. Fuentes para su conocimiento [ver n. 6], pp. 137-189. 
orientación escolar de la Orden, evidente, por ejemplo, en el episodio de la «conversión» de Reginaldo de Orleáns. Lo que hace que el Libellus sea fiel a la hora de describir la institución que Domingo había fundado ${ }^{31}$.

En tercer lugar, la bula de canonización presentaba a Domingo -asociado con San Francisco- como un atleta de Dios, a la cabeza de una armada dispuesta a aplastar a la herejía. El texto del documento papal que cerraba el proceso de canonización condensaba el retrato del santo dando especial relieve a su acción al servicio de la Iglesia, que debía ser también la de sus hermanos posteriores. Es aquí donde se destaca con fuerza la lucha contra la herejía, considerada por Gregorio IX como una enfermedad contagiosa. El texto, influenciado por la profecía joaquinita, proponía una teología de la historia de carácter apocalíptico, sobre la visión de Zac 6,1-9, qué distinguía cuatro épocas en la historia de la Iglesia, según los protagonistas asociados con los caballos qué tiraban las cuadrigas aparecidas al profeta: en primer lugar los mártires, anunciados por los caballos rojos; después los monjes de San Benito, de quién eran imagen los negros; seguidos por los cistercienses y por los florenses -es decir la orden fundada por Joaquín de Fiore, famoso por sus previsiones acerca del fin de los tiempos- blancos como los caballos de la tercer cuadriga; por último, antes de la puesta del sol llegaban los frailes predicadores y los menores, encarnados en el último grupo de caballos variados y robustos ${ }^{32}$.

Por lo tanto, de esos tres conjuntos documentales ligados al proceso de canonización, se desprenden tres imágenes de Santo Domingo: el vir evangelicus, fundador de una suerte de colegio universitario, a partir del escrito de Jordán de Sajonia; Santo Domingo el fraile observante, presente en las deposiciones de los testigos de la investigación oficial; y Santo Domingo como el héroe del combate antiherético, a partir de la documentación pontificia.

La dificultad para promover el culto de Santo Domingo a partir del complejo contenido del Libellus obligó a los Predicadores a reescribir constantemente la

31 Giulia Barone considera que el Libellus «non sia stato pensato originariamente como uan storia degli inizi dell'Ordine, rivolto a tutti i confratelli, como si dovrebbe dedurre del prologo, ma come una serie di appunti, dal valore quasi esclusivamente personale, un work in progress, cui Giornado aggiungeva, quando se ne presentava l'occasione, particolari o notizie che gli sembravano degne di menzione. Ritengo che così andrebbero lette anche le informazioni riguardanti Domenico, i suoi ultimi giorni di vita e le esequie cui aveva partecipato il futuro Gregorio IX, in quella fase legato papale in Lombardia». Giulia BARONE, Il Libellus de initio ordinis fratrum praedicatorum, en Domenico di Caleruega e la nascita dell'Ordine dei Frati Predicatori... [ver n. 8], pp. 431-440 [439].

32 Lorenzo Galmes y Vito T. GómEZ, Santo Domingo de Guzmán... [ver n. 6], pp. 190-194. 
legenda de su fundador. De este modo, se encargó a Pedro Ferrando la redacción de una Vida de Santo Domingo, que fue revisada y aprobada por el capítulo general de 1238 en vista de su uso litúrgico ${ }^{33}$. Su primera preocupación fue evacuar del texto todos los elementos que no concernían directamente a Domingo, a fin de convertirlo en el personaje central de la hagiografía. A ello agregó la lista de milagros post mortem y el relato de la traslación de las reliquias del santo ordenada por el capítulo general de 1233.

Los primeros frailes habían sido reclutados en el ámbito universitario y, por lo tanto, siendo clérigos intelectuales, no habían promovido hasta entonces la veneración cultual del santo fundador. Circunstancia que también se relacionaba con una actitud distante, reticente y crítica frente al uso que los Menores habían hecho de la santidad de San Francisco. Sólo a partir de mediados del siglo XIII, la Orden revalorizó los aspectos miraculosos y taumatúrgicos ligados a Domingo ${ }^{34}$. Cuestiones que se manifiestan en la segunda revisión de la legenda oficial, que hizo el obispo dominico Constantino de Orvieto hacia $1247^{35}$. El texto de Constantino aporta numerosos aspectos de la santidad heroica y algunos milagros realizados por Santo Domingo en vida, tomados de las actas del proceso tolosano de canonización y de la colección de milagros encargados por el Capítulo General de 1245. A diferencia de Jordán, se esfuerza por atribuir a Domingo, y no a Diego de Acebes, todos los méritos en la fundación de la Orden.

La última revisión de la legenda oficial de Santo Domingo, realizada durante el generalato de Humberto de Romans en el cuadro más amplio de una reforma litúrgica, quitó los agregados realizados por Constantino, pero introdujo la atribución de la fundación de Prouille a Domingo, y no a Diego, con el fin de exaltar el prestigio del santo fundador ${ }^{36}$.

33 Petri Ferrandi, Legenda sancti Dominici, S. Tugwell op (ed.), Roma, 2015 (Lorenzo Galmes y Vito T. GómEZ, Santo Domingo de Guzmán... [ver n. 6], pp. 219-248).

34 Luigi CANETTI, L'invenzione della memoria. Il culto e l'immagine di Domenico nella storia dei primi frati Predicatori, Roma, 1996, pp. 488-489.

35 Constantini Urbevetani, Legenda sancti Dominici, H. C. ScheEben (ed.), Roma, 1935, pp. 260352 (Lorenzo Galmes y Vito T. GómEZ, Santo Domingo de Guzmán... [ver n. 6], pp. 249-290).

36 Humberti RomanIs, Legendae sancti Dominici, necnon Materia praedicabilis pro festis sancti Dominici et testimonia monora de eodem, adiectis miraculis Rotomagensibus sancti Dominici et Gregorii IX bulla canonizationis eiusdem, Simon TUGWELl OP (ed.), Roma, 2008 (Lorenzo GaLMES y Vito T. Gómez, Santo Domingo de Guzmán... [ver n. 6], pp. 291-330). En 1255, el Capítulo General se decidió por una colección de historias dominicanas. Gerardo de Frachet recibió el encargo del maestro de la Orden, Humberto de Romans, de escribir esta colección en 1256. Entregó su texto completo a Humberto de Romans en el capítulo general de 1259, después de presentar una primera versión en 1258 , pero con motivo del capítulo, se insertaron varios relatos adicionales, 
Etienne de Salagnac, en su tratado de las glorias de la Orden escrita en su convento de Limoges en 1277, cita textualmente la bula de canonización y la glosa, con el fin de definir la misión de los frailes. En un momento en que la identidad de la Orden se cristalizaba en torno a la idea de misión y en particular de la actividad inquisitorial, hasta entonces secundaria.

Por último, las deposiciones «boloñesas» del proceso de canonización, fueron incorporadas in extenso en la nueva Vida de Santo Domingo, del turingiano Thierry d'Apolda, escrita a finales de la década de $1280^{37}$. Allí también se incorporaron otras fuentes hasta entonces inéditas, como los milagros de sor Cecilia y los nueve modos de orar de Santo Domingo, en un momento en que se producía el nacimiento de una hagiografía de tipo erudita, más preocupada por descubrir y divulgar la existencia de nueva documentación.

A principios del siglo XIV, Bernard Gui ${ }^{38}$ y Galvano Fiamma ${ }^{39}$ escribieron las crónicas más importantes de la Orden, que fueron ampliamente utilizadas por los autores dominicos posteriores. De hecho, dos manuscritos castellanos de finales del siglo XIV y principios del XV respectivamente, reflejan la gran influencia que ejercieron en estos textos. Se trata, por un lado, de un texto perteneciente al monasterio de Santo Domingo el Real de Madrid, de autor

cuya redacción se confió a Gerardo. Mientras tanto, Humberto de Romans comenzó su propia revisión de toda la obra y, hasta el capítulo general de 1260, se agregaron otros relatos. El padre Tugwell, considera que nunca ha habido un texto definitivo de la Vite Fratrum. Lo que se encuentra en los manuscritos de Vite Fratrum es una mezcla de varios intentos de escritura y las sugerencias, correcciones y comentarios de los lectores a quienes Humberto había confiado el texto. Hay una edición de la Vite Fratrum, realizada por Benedict Maria Reichert en la Monumenta Ordinis Fratrum Praedicatorum (MOPH). El P. Reichert no había comprendido la estructura de la tradición manuscrita de la Vite Fratrum. Va acompañada de la de dos crónicas de la Orden. La Crónica prior, ciertamente fue escrita por Gerardo: adjuntada por primera vez a su crónica universal, fue transferida a la Vite Fratrum en 1258. La Crónica posterior se suele atribuir a Humberto de Romans. Esta crónica existe solo en el contexto de la Vite fratrum, del cual siempre ha sido parte integral, y aparece solo en el contexto de la segunda revisión de la Vite fratrum emprendida por Humberto en 1260. Pedro Ferrando ya había muerto en 1258. La atribución tradicional a Humberto es ciertamente correcta. La traducción al español en Lorenzo GALMES y Vito T. GÓMEZ, Santo Domingo de Guzmán... [ver n. 6], pp. 369-656.

37 En cuanto al Liber de vita et obitu et miraculis sancti Dominici et de ordine quem institucit de Thierry de Apolda, hay al menos dos tradiciones, una tradición italiana y una tradición alemana. Dentro de esta segunda tradición, hay varios ensayos de Thierry, en particular un ensayo largo y un ensayo corto. Sólo está disponible una edición, realizada por el P. Cuypers en el Acta Sanctorum, de un único manuscrito de la tradición alemana.

38 Bernardi Guidonis, Scripta de Sancto Dominico, Simon Tugwell op (ed), Rome, 1998.

39 Galvano FIAMMA, Chronica Ordinis praedicatorum ab anno 1170 usque ad 1333 [Chronica parva], Benediktus M. REICHERT OP (ed.), Roma, 1897. 
anónimo, y por otro, de una breve crónica atribuida a fray Luis de Valladolid. Por lo tanto, son dos obras escritas durante el Cisma por los dominicos de obediencia clementista.

La primera obra es un códice misceláneo perteneciente al monasterio de Santo Domingo el Real de Madrid, en el que se encuentra, entre otras cuestiones, la primera Vida de Santo Domingo escrita en castellano ${ }^{40}$. Específicamente se incluyen: Vida y milagros; Relación de milagros referidos por la beata Cecilia a sor Angélica; Declaraciones de los Testigos de Bolonia y de Languedoc de su canonización; Modos de Orar, con nueve viñetas ilustrativas; Más milagros. En su mayor parte extraídos de la obra de Gerardo de Franchet y, sobre todo, de Humberto de Romans.

Su finalidad era devocional, litúrgica o paralitúrgica, pues contiene textos para ser leídos, entonados y consultados; esto es, bien para la lectio ad prandium (sin excluir la lectura mientras se realiza algún trabajo manual ni la lectura privada), para el rezo, para la meditación o la consulta para preparar la predicación. El códice tiene algo de leccionario hagiográfico y de legendario tradicional, compuesto a partir de textos anteriores identificados o de autor conocido ${ }^{41}$.

Por su parte, Luis de Valladolid (m. 1436) es el autor de la Tabula quorumdam doctorum ordinis praedicatorum ${ }^{42}$. Este fraile pertenecía al convento de San Pablo de Valladolid, donde había hecho sus primeros estudios, que luego siguió en Tolosa y París. Se convirtió en maestro de teología hacia 1416. Entre 1419 y 1423 fue prior provincial de la provincia de Hispania. Se trataba de un fraile vinculado a la corte del rey Juan II. De hecho, sirvió como teólogo del monarca ante el Concilio de Constanza y también como embajador real. Posteriormente se convirtió en confesor y consejero del monarca castellano ${ }^{43}$. Es interesante que este fraile encontrase el tiempo y la inclinación para escribir este texto durante sus estudios de teología en París, es decir, entre 1412 y 1413, cuando estaba le-

40 Recoge la narración de la vida y milagros de su fundador, de San Pedro Mártir y de Santo Tomás de Aquino -que eran los miembros de la Orden de Predicadores canonizados en ese tiempo-, junto con algunos textos litúrgicos y de lectura espiritual. Teresa BARBADILLO DE LA FUENTE, Vida de santo Domingo de Guzmán del códice de Santo Domingo el Real de Madrid, en Archivo Dominicano, XXXVII (2016), pp. 13-94.

41 Véase, Guy PHILIPPART, Les légendiers latins et autres manuscrits hagiographiques, Typologie des sources du Moyen Âge occidental, Turnhout, 1977.

42 Cronica fratris Ludovici de Valleoleto, en Analecta sacri ordinis fratrum praedicatorum, 20 (1931-2), pp. 727-761, 801-8.

43 Véase, Juan Prieto Sayagués, El acercamiento de la monarquía castellana a la Orden de los Predicadores durante el reinado de Juan II de Castilla (1406-1454), en En la España Medieval, 39 (2016), pp. 197-224. 
yendo las Sentencias de Pedro Lombardo en este importante centro de estudios dominico.

La Tabula, tal como sobrevive en los manuscritos, es esencialmente una compilación de documentos históricos y hagiográficos relacionados con la Orden dominica, completada con una lista de autores dominicanos con sus escritos. Una mirada al contenido demuestra que la Tabula sirvió principalmente a la comunidad dominica de St. Jacques en París, donde vivía fray Luis en el momento de escribirla, por ello se detiene en las biografías de Alberto Magno y Tomás de Aquino, y dedica un largo apartado a la misma historia del convento parisino.

\section{LOS OBSERVANTES COMO VERDADEROS HEREDEROS DE SANTO DOMINGO}

Ante todo, ¿qué fue exactamente la reforma observante? La respuesta de los dominicos observantes, es que se trataría de un retorno a la observancia de la regla agustina y de las constituciones como habían sido escritas y seguidas por los primeros frailes predicadores. En palabras de Raimundo de Capua:

La palabra reforma en su sentido propio significa que un objeto vuelve a tomar la forma que tenía antes. Entonces, cuando hablo de la reforma de nuestra Orden, no puedo pensar en una mejor manera de llevarla a cabo que mirando a la Roca y a la Cantera de la cual fuimos hijos: es decir, a ese Abraham «Padre de muchos», el Beato Domingo que es nuestro padre por el Espíritu Santo, y a esa Sara, nuestra Santa Orden que es nuestra madre ${ }^{44}$.

Sin embargo, hoy sabemos que la reforma observante no fue un «simple» retorno a la adhesión a las reglas originales. La sociedad había cambiado bajo la influencia de la crisis del siglo XIV y de otros acontecimientos. Los miembros del clero regular tuvieron que redefinir su misión dentro de la Iglesia y de la sociedad. Además, la observancia de la regla y de las constituciones «originales» no era tan sencilla en el caso de los dominicos, ya que sus constituciones dejaban mucho espacio para las dispensas y, por lo tanto, para las excepciones. De allí que, la reforma observante puso énfasis en aspectos específicos, adaptados a las necesidades contemporáneas. Se crearon nuevos modelos de santidad y se emitieron nuevas bulas, en las que se enfatizó la importancia de aspectos nunca experimen-

44 Raimundo DE CAPUA, Opuscula et litterae, Roma, 1895, p. 54. 
tados hasta entonces, como la estricta clausura, o, específicamente en Castilla, los estatutos de limpieza de sangre. Al mismo tiempo, no debemos considerar a la observancia como un movimiento coherente: hubieron iniciativas e ideas de reforma en competencia ${ }^{45}$.

Solo después de la erección de las congregaciones de la reforma los observantes se volvieron más autónomos e influyentes ${ }^{46}$. Se considera, por lo tanto, al período comprendido entre 1380 y 1460 como un período inicial, durante el cual algunos maestros generales, como Bartolomé Texier, intentaron impulsar la reforma, pero sin avanzar mucho en la mayoría de las provincias. Aunque los observantes dominicos obtuvieron vicarios propios y recibieron algunos privilegios adicionales, solo tenían una independencia institucional limitada. Los privilegios concedidos por un papa podrían ser anulados por su sucesor. En cambio, con el pontificado de Pío II se inició una nueva etapa en la observancia dominicana. En 1461, Pío II canonizó a Catalina de Siena, la «madre» de la observancia dominica. Además, apoyó la creación de congregaciones observantes, que finalmente alcanzaron un alto grado de independencia. En el siglo XVI, las congregaciones fueron abolidas y transformadas en provincias reformadas, que hicieron que el «modelo observante», acuñado en el siglo XV, fuera dominante. Un proceso que se hizo visible también en las narrativas de la Orden ${ }^{47}$.

Las primeras constituciones dominicas de 1220 enfatizaban que la Orden se había fundado «precisamente por el bien de la predicación y la salvación de las almas». Por supuesto, la regla agustina debía seguirse, pero el objetivo principal era ser útil a la sociedad cristiana. Cuando Raimundo de Capua (1380-1399) puso la reforma de la Orden en la agenda dominica, se insistió sobre esta cuestión. A los ojos de Raimundo, la observancia dominica no solo implicaba que los frailes fueran obedientes, castos y pobres (observancia regular), sino también que colaboraran activamente en la salvación de las almas. Tal como señala Isabella Gagliardi, la bula Fons sapientiae, con la que Gregorio IX había canonizado a Santo Domingo

45 Bert Roest, Observant Reform in the Late Medieval Religious Orders, en Miri RuBIN y Walter SimOns (ed), The Cambridge History of Christianity, Volume 4: Christianity in Western Europe, c.1100-c.1500, Cambridge, 2009, pp. 446-457; James MIXSON y Bert ROEST (ed.), A Companion to Observant Reform in the Late Middle Ages and Beyond, Leiden, 2015.

46 Sara FASOLI, Tra riforme e nuove fondazioni: l'Osservanza domenicana nel ducato di Milano, en Nuova rivista storica, 76 (1992), pp. 417-494.

47 Sobre la reforma de la Provincia de España véase Guillermo NiEVA OCAMPO, Las reformas de la orden de predicadores en Castilla durante el siglo XV. Movimientos, programas, actores y resultados, en Emilio Callado Estela (ed.), Frailes, santos y devociones. Historias dominicanas en bomenaje al Profesor Alfonso Esponera, Valencia, 2020, pp. 203-238. 
(3 de julio de 1234), consideraba que la Orden de los Frailes Predicadores había sido suscitada por Dios para acompañar a la humanidad en el último viaje a la salvación. Por lo tanto, el retorno a los orígenes -la observancia- revitalizaría ese destino providencial de la Orden ${ }^{48}$. Con este fin, los frailes tenían que «seguir los pasos de nuestros santos antepasados en la Orden, los hombres que la fundaron y la desarrollaron de manera coherente». Y de este modo, utilizaron la historia para probar esa afirmación. En consecuencia, el objetivo común de la historiografía dominica a partir de la reforma fue la exaltación de la Orden, dado que su función principal era proporcionar ejemplos de vida ${ }^{49}$.

Por otro lado, los cronistas observantes tendieron a dedicar la mayor parte de su atención académica al siglo de la fundación, ya que consideraban que su propio estilo de vida se ajustaba a las reglas e instituciones de Santo Domingo y los primeros padres. Es decir, miraban a ese pasado en el que las normas habían surgido y supuestamente se habían cumplido plenamente, aunque solo fuera para legitimar su propio esfuerzo reformista, como si este estuviera vinculado al pasado temprano de la Orden.

La formación humanista de Girolamo Borselli (m. 1497) y de Ambrosius Taegius (m. después de 1525), los principales cronistas dominicos de la época, hizo posible que escribiesen obras críticas, suficientemente documentadas, como verdaderos historiadores «modernos». De hecho, en sus escritos se observan abiertas críticas hacia las decisiones de los superiores o hacia la actividad de los mismos reformadores ${ }^{50}$.

$48 \ll$ La riforma di cui si parla non si limita alla sola Chiesa intesa come insieme dei consacrati di ogni ordine e grado, bensì si estende alla Chiesa intesa come congregatio fidelium, ovvero all'intera società. La riforma è ineludibile per l'instaurazione della società di giustizia implicita nel sentimento messianico. Non un progetto, dunque, ma molto di più: una profezia perché quella società è un evento destinato a realizzarsi, un evento che nel futuro si realizzerà sicuramente». Isabella GAGLIARDI, Caterina e l'Osservanza domenicana, en Alessandra BARTOLOMEI ROMAGNOLI, Luciano CINELli y Pierantonio PiATTI (coord.), Virgo digna Coelo. Caterina e la sua eredità Raccolta di studi in occasione del $550^{\circ}$ anniversario della canonizzazione di santa Caterina da Siena (1461-2011), Roma, 2013, pp. 361-378 [371].

49 Anne Hujbers, Zealots for souls. Dominican Narratives between Observant Reform and Humanism, $c$. 1388-1517, Berlin, 2018, pp. 183-195.

50 Borselli era partidario de la Congregación observante de Lombardía y se consideraba un fraile observante. En su crónica, defendió la existencia de las congregaciones observantes. Al mismo tiempo, problematizó las categorías «observante» y «conventual». Borselli no ofreció una imagen idealizada y armoniosa de un «movimiento» observante coherente. Según el cronista, algunos conventos que nunca habían sido reformados vivían con mayor honestidad que los llamados conventos reformados de Tuscia que habían recaído. También informó sobre conflictos entre diferentes grupos de frailes observantes. Distinguió entre grupos de reformadores: algunos eran muy observadores, otros menos, y podrían estar en desacuerdo en el curso a seguir. 
Las primeras crónicas impresas de la Orden se realizaron en Venecia bajo la supervisión de Alberto Castello. Su Brevis chronica fue adoptada como la historia oficial de la Orden y estaba destinada a ser distribuida a las casas dominicas en general. Por ende, su contenido difiere de las crónicas manuscritas que solo se guardaban en una biblioteca dominica. Las crónicas impresas de Castello son más breves, contienen menos detalles y no incluyen una discusión de capítulos generales, sino que se concentran en los «dominicos ilustres» que florecieron durante los reinados de la subsecuentes maestros generales. Como era de esperarse, la historia del Orden dominica en el siglo XIII ocupa una parte desproporcionadamente grande de la crónica. Nueve de los catorce capítulos de Brevis chronica tratan del siglo XIII. Los tres primeros capítulos se concentran en el comienzo de la Orden: tratan sobre Santo Domingo y la fundación, y enfatizan el papel providencial de la Orden dominica.

\section{SANTO DOMINGO EN LAS CRÓNICAS DE LOS OBSERVANTES CASTELLANOS}

En el marco de las grandes empresas editoriales promovidas por la Orden en el siglo XVI y sumamente influenciadas por las crónicas italianas escritas por los frailes observantes durante el siglo XV, se escribieron en la Provincia de España las primeras crónicas posteriores a la reforma, me refiero a las obras compuestas por fray Sebastián Olmeda, fray Juan de la Cruz y fray Hernando del Castillo, la primera en latín y las otras dos en español ${ }^{51}$.

Junto con la reforma se había abierto camino un proceso de afirmación de la identidad de las provincias. De allí la proliferación de crónicas locales en el XVI en las que se defiende en términos apologéticos las preeminencias de cada región. En Castilla, las crónicas escritas durante ese siglo destacarían, entre otras cuestiones, la modélica observancia regular del fundador de la Orden, su actividad como predicador enemigo de la herejía -asimilando ello con la actividad inquisitorial-y su origen noble.

De la crónica escrita por Sebastián de Olmeda existen dos versiones: una crónica breve, que solo relata la historia de la Orden hasta el Gran Cisma, que se imprimió en Roma en 1531. En ella, los generalatos de veintidós maestros

51 Vicente Beltrán DE Heredia, Examen crítico de la bistoriografía dominicana en las provincias de España y particularmente en Castilla, en Archivum Fratrum Praedicatorum, 35 (1965), 195-248; Alfonso ESPONERA CERDÁN, Aproximación a la bistoriografía dominicana ibérica desde el Renacimiento hasta la Ilustración (siglos XVI-XVIII), en Archivo Dominicano, 24 (2003), pp. 107-148. 
generales dictan su estructura, que termina con el maestrazgo de Elías de Toulouse. Después de 1531, Olmeda continuó desarrollando la crónica hasta 1550; esta versión ampliada fue escrita en un estilo más «elegante», el prólogo fue diferente, se reescribieron pasajes y se hicieron adiciones. De viris illustribus ordinis praedicatorum de Leandro Alberti (1517) ejerció una influencia indiscutible en su contenido $^{52}$. Fue impresa recién en 1936.

Sebastián Olmeda había ingresado en la Orden de Predicadores en Villada, en la diócesis española de León. En 1505, se encontraba completando sus estudios en el monasterio de Santo Tomás de Ávila, donde entró en contacto con la cultura humanista: el convento abulense era uno de los pocos centros de studia bumanitatis dentro de la Orden dominica. En 1510, Olmeda se encontraba estudiando en el Colegio San Gregorio de Valladolid, fundado por Alonso de Burgos como colegio de teología dominica. Hacia 1531, Sebastián de Olmeda, siendo ya maestro en teología abandonó Castilla para viajar a Roma. Había escrito una crónica que presentó al procurador de la Orden de Predicadores, Juan Fenario, que se convertiría en maestro general al año siguiente.

En el prólogo de su crónica Olmeda critica a aquellos que eran «religiosos», pero sabían más de las hazañas y de las historias de los paganos que de su «propio» pasado. Hizo hincapié en que la Orden dominica contaba con su propio ejército y líderes, y que estos no estaban preocupados por la carne y la sangre, sino por el espíritu y la virtud; siendo su conocimiento «muy útil para ser imitado» ${ }^{53}$.

Olmeda llama al fundador de la Orden Sanctus Dominicus Hispanus, Primus Magister Ordinis. Realiza una síntesis apretada sobre el nacimiento y formación de Domingo, así como de su misión en Languedoc junto a Diego de Acebes.

52 En Valencia y en torno a 1522, Baltasar Sorió (†1557), hombre de gran relieve intelectual, había publicado su De viris illustribus Provinciae Aragoniae Ordinis Praedicatorum, influenciado también por Alberti. Y es que la obra de fray Leandro Alberti fue muy pronto conocida en España. Existen ejemplares de la edición de 1517 en la Biblioteca de la Universidad de Salamanca, en la Biblioteca Nacional de España y en la Biblioteca de la Universidad de Sevilla que pertenecieron a conventos dominicos.

53 « Quid enim mihi et magno Alexandro? Quid cum Octaviano Caesare aut turbida Roma gentiumque regibus et qui dominantur orbi? Quid denique cum his qui foris sunt, qui mundo mortuus sum quique me longe diversae potiorique militiae devovi ? Habet namque et ipsa militia nostra duces ac principes suos, et quidem non ignobiles utpote spiritus et virtutis imitatione, et non jam carnis et sanguinis successione, propagatos. Quorum gesta retexere non minus delectabile, imitari vero perutile $\gg$. Sebastián OLMEDA, Nova chronica ordinis praedicatorum de initio videlicet et successu eius ipsiusque Magistris Generalibus et viris illustribus usque ad annum MM qui et est CCCXXX et ultra ab institutione illius, Manuel CANAL GOMEZ (ed.), Roma, 1936, p. 8. 
Pero, sobre todo, describe los orígenes de la Orden, su aprobación y primera expansión. Al finalizar, recuerda que antes de morir Domingo había recomendado a los frailes que observasen:

Charitatem ante omnia mutuam, qua Christi discipuli dignoscuntur, babete; Humilitatem cordis, cui omnia consentiunt et quae ad astra tollit, servate; Paupertatem spiritus, quae ducit ad regna polorum, libenti animo sectamini. Stabiles denique usque in finem in sanctitate manete, et in laetitia ac fervore animi Domino deservite ${ }^{54}$.

El Capítulo General de 1532 había mandado que los superiores mayores colligant nomina virorum illustrium et in proximo capitulo futuro in scriptis tradant. Pero en las actas del Capítulo siguiente de 1536 nada se dice acerca del cumplimiento de la señalada entrega, si bien en Castilla fray Juan de Robles habría publicado su Crónica de la reforma de fuan Hurtado de Mendoza (1543-47) y, más adelante, publicaría fray Juan de la Cruz su Crónica de la Orden de Predicadores (1567).

Fray Juan de la Cruz habría nacido en Talavera de la Reina, hacia $1490^{55}$. Allí vivió hasta que partió en 1517 a estudiar teología en la Universidad de Salamanca, donde conoció a los dominicos del Convento de San Esteban. Siendo clérigo, regresó a Talavera en 1520, donde fue testigo de la fundación del Convento de San Ginés, realizada por fray Juan Hurtado de Mendoza. Profesó el 6 de agosto de 1625 en la comunidad observante de Atocha. Fue enviado a continuar sus estudios en el Colegio de San Gregorio de Valladolid, donde permaneció hasta 1538, cuando se trasladó a Lisboa, junto con otros frailes de origen judeoconverso, obligados a abandonar Valladolid a causa de la imposición de los estatutos de limpieza de sangre por parte del maestro general Fenario ${ }^{56}$. A fray Juan se lo nombró maestro de novicios del convento de Santo Domingo de Lisboa. En los años siguientes, desempeñó también el oficio de prior en ese monasterio y en el de Batalha. Fue durante el priorato de fray Luis de Granada en el convento de Lisboa, entre los años 1556-1560, que recibió el encargo de redactar la Coronica

54 Sebastián OlmEdA, Nova Chronica ... [ver n. 53], p. 22.

55 María Dolores Mira y GÓmEZ DE MERCADO, Actualización, estudio y edición del Diálogo sobre la necesidad de la oración vocal, obras virtuosas y santas ceremonias de fray fuan de la Cruz (1555), Almería, 2012, pp. 29 y ss.

56 Formalmente, el maestro general Juan Fenario (Jean Feynier), había enviado a veinte frailes afines al espíritu del padre Hurtado, dirigidos por fray Jerónimo de Padilla para introducir la reforma, un pedido realizado por el rey Juan III. Véase, Vicente BELTRÁn DE HEREDIA, Historia de la reforma de la provincia de España, Roma, 1939, pp. 220-240; Guillermo NIEVA OCAMPO, Frailes revoltosos: corrección y disciplinamiento social de los dominicos de Castilla en la primera mitad del siglo XVI, en Hispania. Revista española de historia, 72 (2011), pp. 39-64 [61-62]. 
de la orden de predicadores, obra que terminó antes de morir, hacia 1562, y que fue publicada en Lisboa en el año $1567^{57}$, en los talleres tipográficos de Manoel João, activo en la capital portuguesa entre 1565 hasta 1569, y desde entonces y hasta 1672 en Viseu $^{58}$.

Gran parte de la crónica se inspira en el Chronicon partibus tribus distincta ab initio mundi ad MCCCLX, publicado en 1477, obra del arzobispo florentino Antonino Pierozzi (San Antonino de Florencia), y también en el Libellus... de Jordán de Sajonia (1222-1237), y en la Legenda Sancti Dominici, de Humberto de Romans (1260). Al igual que en Olmeda, otra fuente de fray Juan es la obra de Leandro Alberti (1479-1552) $)^{59}$, De viris illustribus ordinis praedicatorum libri sex in vnum, que había sido publicada en Bolonia en 1517:

del cual yo he sacado buena parte de lo que aquí he escrito: y pues él tuvo tan religioso celo de la honra de la orden y de los padres que la decoraron, justo fue que en la misma historia se recompensase su trabajo con hacer de él me-

57 María Dolores Mira y Gómez de Mercado, Actualización, estudio y edición del Diálogo... [ver n. 55], pp. 155 y ss. El cardenal-infante Enrique fue un notable promotor de la reforma de las órdenes religiosas en Portugal, también de la reforma de la inquisición y de la mejora de la actividad pastoral en general. Para ello, prestó su apoyo a fray Luis de Granada y a la recientemente fundada Compañía de Jesús. Véase, Amelia POLÓNIA, Espaços de intervenção religiosa do Cardeal Infante D. Henrique: Actuação pastoral, reforma monástica e inquisição, en Inês AMORIN y otros (coords.), Em torno dos espaços religiosos monásticos e eclesiásticos: actas do Colóquio de Homenagem a Frei Geraldo Coelho Dias, Oporto, 2005, pp. 17-37 [26].

58 ACADEMIA DAS CIÊNCIAS DE LISBOA, Memorias de litteratura portugueza, v. 8, Lisboa, 1812, p. 110 y 128; Mário DA CoSTA RoQUE, Livros antigos viseenses. Século XVI, en Beira Alta, 23 (1964), pp. 71-76. En Viseu, Manoel João sirvió al obispo Jorge de Ataíde, discípulo del jesuita Bartolomeu Guerreiro, e hijo de don Antonio de Ataíde, conde de Castanheida, privado de Juan III. Los Ataíde integraban el partido español en la corte lusitana a partir del reinado de don Sebastián, junto con los Castro de Évora. De hecho, don Jorge pasó a desempeñarse en 1578 en la casa real como capellán mayor del rey-cardenal don Enrique. Estuvo al frente de la capilla portuguesa hasta su muerte, ocurrida en Castanheira el 17 de enero de 1611. También fue Presidente del Consejo de Portugal y Limosnero mayor durante el reinado de Felipe II y Felipe III. Véase, Félix LABRADOR ARROYO, La casa real portuguesa de Felipe II y Felipe III: la articulación del reino a través de la integración de las elites de poder (1580-1621), v. II, Madrid, 2006 [tesis inédita], pp. 665-667; Compendio Historico do Estado na Universidade de Coimbra, Lisboa, 1772, pp. 19-22.

59 «All'inizio del 1516 mandò a G. A. Flaminio le biografie dei maestri generali, dal beato Giordano di Sassonia al Gaetano, composte nello spazio di dieciotto giorni, mentre attendeva anche alla predicazione (cfr. De viris illustribus..., f. 23r; le biografie comprendono i ff. 23v-50v). Nella dedica, scritta il 10 genn. 1516, l'Alberti accenna alla sua attività storica precedente: '... iam quindecim diversarum rerum occurrentium aetatis nostrae libros cum compluribus commentariis, post quorundam virorum illustrium vitas, post Ephemerides, quas prae manibus habeo, absolvi'. L'opera che doveva uscire nel 1516 -terzo centenario dell'approvazione dell'Ordine domenicano- comparve invece l'anno seguente». Abele L. REDIGONDA, Alberti, Leandro, en Dizionario Biografico degli Italiani, vol. 1, 1960, http://www.treccani.it/enciclopedia/leandro-alberti_(Dizionario-Biografico). 
moria, y loarle en su grado con los claros varones para que (según el Apóstol) goce el labrador del fruto de la tierra que labra, y coma el buey de la parva que trilla ${ }^{60}$.

De este autor tomó prestada la información sobre los santos, los papas, los cardenales y los obispos vinculados a la Orden a partir de la segunda mitad del siglo XIII (San Pedro Mártir, Papa Benedicto XI, Santo Tomás de Aquino, San Vicente Ferrer, el Beato Simón de Rímini, etc.) así como de los maestros generales hasta Tomás de Vio Cayetano ${ }^{61}$.

El libro estaba destinado al príncipe Carlos, por aquel entonces heredero de Felipe II, a quien fray Juan de la Cruz solicita el «amparo y remuneración» para la Orden, por los servicios que Santo Domingo y su familia religiosa habían realizado a la cristiandad y «particularmente a estos reinos, que esperamos por divina disposición serán vuestros». Un pedido realizado en el contexto de una gran crisis en la Orden, a raíz de la sentencia a muerte de fray Francisco de Rojas y también por el proceso inquisitorial contra el arzobispo Bartolomé de Carranza. Pero también a un príncipe cuyo entorno portugués era políticamente afín con el autor de la crónica y con fray Luis de Granada, quien había ordenado su impresión ${ }^{62}$.

Fray Juan consideraba al hecho narrativo como instrumento didáctico de primer orden:

ca no todos gustan los libros de doctrina, ni todos pueden sacar fruto de ellos por la desproporción del estilo o de la materia que tratan a su capacidad [pero] la Historia enseña sin sutileza de argumentos y razones dificultosas, mas con ejemplos palpables de obras comunes en que los hombres se suelen ejercitar, y pone delante los hechos de los antiguos tan llanamente que en alguna manera parece que los presenta a la vista y nos hace conversar con los pasados como si en su tiempo viéramos [...] Porque manifiesto es que la doctrina enseñada por ejemplos y muestras de obras es más poderosa para provocar a su seguimiento que la que se comunica por razones y arte de decir ${ }^{63}$.

60 Juan DE LA CRUZ, Coronica de la Orden de Predicadores, de su principio y sucesso hasta nuestra edad y de la vida del bien auenturado sancto Domingo su fundador y de los sanctos y varones memorables $q$ en ella florecieron, Lisboa, 1567, f. CXXX r.

61 Sobre las fuentes que utilizan los cronistas italianos de la Orden véase, Raymond CREYTENS, Les écrivains dominicains dans la chronique d'Albert de Castello, en Archivum Fratrum Praedicatorum, 30 (1960), pp. 227-259.

62 José MARTíneZ Millán, Familia real y grupos políticos: la princesa doña fuana (1535-1573), en ID. (dir.), La corte de Felipe II, Madrid, 1994, pp. 73-105; Gerardo MORENO EsPINOSA, Don Carlos: el príncipe de la leyenda negra, Madrid, 2006, pp. 51 y ss.

63 Juan DE LA CRUZ, Historia de la Iglesia, que llaman eclesiástica y tripartita. Abreviada y trasladada de Latin en Castellano por un religioso de la orden de Santo Domingo, Y abora nuevamente revisada y corregida por el mesmo intérprete, Coimbra, 1554, fol. aiij r. 
De allí que su crónica fuese sobre todo un recurso pedagógico, pensado para la formación de los frailes en general. En consecuencia, los primeros capítulos se pueden caracterizar como un riguroso recuerdo de los principios básicos de la identidad institucional de los dominicos, mayormente al evocar la vida santa y ejemplar de Domingo, el primus institutor, al que no se quiere convertir solamente en el mero fundador de una religio, caracterizada por una nutrida presencia de intelectuales del ámbito universitario, sino en padre de la institutio regularis y en exemplum fulgide, destacando su profunda caridad, la asidua devoción, la simplicitas como pureza y humildad de corazón, y la misma pobreza voluntaria de Domingo, que surgen en la lectura de Juan de la Cruz como valores primarios en el que los frailes deberán reflejar su conducta para cumplir con las observancias a la que los llama el hábito que han elegido vestir. A modo de ejemplo el siguiente fragmento:

[Santo Domingo] era pacientísimo en las adversidades, no solamente en la que le venían por la malicia de los hombres que perseguían su persona y su orden, mas en algunas tribulaciones que le enviaba el Señor para que mas se perfeccionase [...] Nunca alguno le vio airado ni mudado su alegre semblante, sino quando se movía a compasión de alguna miseria [...] Amaba en grande manera la virtud de la pobreza, así en su persona, como en su orden. En invierno y en verano traía, una sola ropa de paño vilísimo, y el escapulario corto, el qual nunca quería cubrir con la capa, aunque estuviese delante de grandes señores: y tal era en todo el tratamiento de su persona, que como vestía, así comía. En su orden mandaba que tuviesen los edificios bajos, y de poca costa, y de ninguna curiosidad, y le pesaba mucho quando veía lo contrario: y que sus frailes se vistiesen de paños viles, y no tuviesen curiosidad, ni copia de libros, ni de otras alhajas en sus celdas. No quería aceptar algunas posesiones y rentas que le daban para los conventos: antes mandó que en su orden viviesen mendigando, y en las iglesias no consentía que tuviesen ricas piezas, cálices, o Cruces de oro, ni engastados de piedras preciosas, ni cortinas, ni ornamentos de brocado y seda para ostentación de riqueza, y para complacer a la vista de los hombres, mas quería que en todo mostrasen el amor a la pobreza. Muchas veces pedía limosna por las puertas, y quando se la daban volvía humildemente gracias por ella, y muchas veces la recibía hincado de rodillas. Era cosa de maravilla, que en las noches siempre gemía y derramaba muchas lágrimas [...] y de día siempre andaba alegre y con cara (como dicen) de Pascua y de graciosa conversación, así con sus frailes, como con seglares y grandes señores: pero nunca con unos ni con otros hablaba palabras ociosas, más siempre de edificación ${ }^{64}$.

64 Juan DE LA CRUZ, Coronica... [ver n. 60], ff. XXIXv, XXXr. 
Por lo tanto, el Domingo que nos presenta Juan de la Cruz es un ejemplo perfecto de entrega y obediencia a los principios esenciales de la regla de San Agustín y de las constituciones.

Por otro lado, frente a los cátaros se presenta al fundador debatiendo, dando testimonio de su pobreza o comprometiendo su persona -al ofrecerse para ser vendido como esclavo con el objeto de salvar un caballero de la herejía y atraerlo a la fe- al contrario de la imagen que se había creado en época de la Congregación de la reforma, cuando se había representado a Santo Domingo condenando herejes desde una tribuna, enviándolos al rogo y a la hoguera, o incluso presidiendo un Auto de $\mathrm{Fe}^{65}$.

El Capítulo general de 1569 encomendó al Maestro de la Orden que, además de coleccionar las Actas de los Capítulos generales e imprimirlas, $u t$ deputet aliquos Patres ad hoc idoneos, qui diligenter colligant ex omnibus partibus Ordinis gesta Patrum, et subinde cronicam magnarn conficiant ad totum Ordinem pertinentem $^{66}$. De este modo, el Capítulo provincial de España de 1571 ordenó que las fuentes documentales de sus Conventos se concentrasen en el de San Esteban de Salamanca. Por su parte, el Capítulo general de 1583 insistió: Committimus onmibus Reverendis Patribus Provincialibus, ut alicui erudito et praestanti viro ex sua Provincia iniungant, ut quae in suis Provinciis aliquando contigerunt et contingunt, scribat, maxime martirum et fidem praedicantium, ut buiusmodi omnibus a Patre Generali receptis universalem quandam memoriam rerum omnium Ordinis componere faciat ${ }^{67}$.

Con muchos años de retraso, durante el reinado de Felipe II y en plena época confesional se publicó La primera parte de la Historia de Santo Domingo y su Orden de Predicadores (1584), escrita por el padre Hernando del Castillo ${ }^{68}$. La obra formaba parte de un programa de respuestas católicas dadas por la corte española a la edición de las Centurias de Magdeburgo, editadas por el luterano Mattias Flac-

65 Tal como representó Pedro Berruguete, por encargo de los frailes, al santo fundador en la iglesia del monasterio de Santo Tomás de Avila. Véase, Sonia Caballero Escamilla, Los santos dominicos y la propaganda inquisitorial en el convento de Santo Tomás de Ávila, en Anuario de estudios medievales, 39, 1 (2009), pp. 357-387

66 Acta Capitolorum Generalium Ordinis Praedicatorum, Benedikt M. REICHERT (ed.), t. IV, 1901, v. 102.

67 Acta Capitolorum Generalium... [ver n. 66], v. 245.

68 Durante el reinado de Felipe II desde la corte se promovió la redacción de crónicas de «España» para enaltecer el prestigio de la Casa de Austria y la obra evangelizadora universal de los españoles. Véase, Richard KagAN, Los cronistas y la Corona. La política de la Historia en España en las edades Media y Moderna, Madrid, 2010, pp. 141-180. 
cio a partir de $1560^{69}$. Del mismo modo que aquella obra, la crónica de Castillo debía redactarse por centurias. Sin embargo, éste logró publicar solamente dos volúmenes antes de morir en 1593.

Hernando del Castillo había profesado en el convento de San Pablo de Valladolid en 1544 y, a partir de entonces, realizó sus estudios de Teología en el Colegio de San Gregorio de la misma ciudad. En 1562 fue hecho presentado. Poco tiempo después entraría al servicio de la Princesa Juana de Austria, como se sabe, líder del partido portugués en la corte real, que seguía una espiritualidad recogida y fomentaba a la recientemente fundada Compañía de Jesús ${ }^{70}$. Sus dotes lo llevaron a predicar en palacio con asiduidad a partir de 1563 . Desde 1568 , por pedido del rey, se incorporó como predicador real en la corte madrileña, siendo agregado al convento de Atocha, del que sería prior ${ }^{71}$. Se desempeñó como calificador del Santo Oficio y como consejero real en numerosas ocasiones, siendo enviado también a misiones diplomáticas, como la que realizó en 1578 ante el rey Enrique de Portugal para preparar la sucesión de Felipe II. Todos los cronistas de la época concuerdan en afirmar que este fraile era un hombre sensato y sin rastro de adulador. A pesar de ser hermano de hábito con fray Diego de Chaves -confesor real y uno de los líderes del partido «castellanista», sostenedor de una espiritualidad formalista y cristiano-vieja- reprochaba a este su obsecuencia con algunas decisiones moralmente condenables del monarca. Hizo observaciones e informes favorables sobre la reforma del Carmelo Descalzo y otras cuestiones solicitadas por el rey. Desde 1581 volvió a residir en el convento de San Pablo de Valladolid, quizás hastiado de la vida de la corte y ciertamente enemistado con Chaves, donde se desempeñó como prior y también rector de estudios. Igualmente, siguió siendo requerido su consejo en la corte y se mantuvo su condición de predicador real. Murió en el convento de Atocha el 29 de marzo de $1593^{72}$.

69 Vicente BELTRÁN DE HeREdiA, Examen crítico de la bistoriografía dominicana en las Provincias de España y particularmente en Castilla, en Archivum Fratrum Praedicatorum, XXXV (1965), pp. 195248.

70 José Martínez Millán, Familia Real y grupos políticos. La princesa Doña Fuana de Austria (15351573), en José Martínez MiLlán (dir.), La corte de Felipe II, Madrid, Alianza, 1994, pp. 73-106.

71 Durante esos años participa en la fundación del Convento de Santo Tomás de Madrid, en acuerdo con fray Diego de Chaves, confesor de Felipe II, y con fray Juan de las Cuevas, provincial y posteriormente confesor del archiduque Alberto. Sobre las alineaciones políticas en la corte de Felipe II véase, José MARTíNEZ MiLlán, El confesionalismo de Felipe II y la Inquisición, en Trocadero: Revista de historia moderna y contemporánea, 6-7 (1994-1995), pp. 103-124.

72 Miguel Ángel Medina Escudero, Hernando del Castillo, en Diccionario Biográfico Español, http:// dbe.rah.es/biografias/18367/hernando-del-castillo 
Castillo era un fraile observante y, de hecho, en su convento ocupaba una celda pobre, con un Cristo de tabla y libros necesarios sin género alguno de adornos, ni esteras, reparo bien decente para los fríos bien rigurosos de Castilla la Vieja. Atrapaba su cuerpo con una capa grosera; lo que de curiosidades y alhajuelas venía a sus manos, de los muchos señores que le comunicaban, remitía al convento; adornaba la sacristía y repartía entre pobres; excusaba todas pláticas no necesarias, muy recogido a la oración y estudio. Levantábase a maitines y, rezados, tomaba largos ratos para la oración y otros para el estudio, alternando de una ocupación en otra hasta la mañana [...] dormía de ordinario vestido, con el sueño era parco, no siendo regalado. Celebraba muy de mañana, la primera o segunda misa, leía su lección de siete a ocho y a la cuaresma tres días pan y agua solamente, seguía el común del refectorio sin más alivio, sin más alivio [...] Vestía lana en cama y persona, sin dejarla ni en enfermedades ${ }^{73}$.

Durante los años en que Castillo escribió su obra se desarrollaba en la provincia dominica una agria disputa interna, que cobró relevancia en el año 1581. El Capítulo provincial que los dominicos tuvieron ese verano en Valladolid puso al descubierto los enfrentamientos y divisiones existentes en la Orden de Predicadores, ya que fray Diego de Chaves consiguió que el rey presionara al maestro general para que nombrase un visitador de la Provincia de España, para así suspender la elección del provincial que había recaído en fray Domingo de Ulloa, prior del convento de San Pablo de Valladolid, quien lideraba a la mayoría de los priores de aquel momento, críticos con la participación política de numerosos dominicos y también descontentos con la notable influencia que ejercían en la Orden los frailes de San Esteban de Salamanca, adictos al programa confesional de Felipe $\mathrm{II}^{74}$. Chaves ganó la partida, puesto que el rey alejó a Ulloa de España, enviándolo como obispo de Nicaragua ${ }^{75}$. Fue justamente en este contexto cuando Hernando del Castillo decidió abandonar la corte madrileña y retirarse al convento vallisoletano.

73 Gonzalo De ArRIAGA, Historia del Colegio de San Gregorio de Valladolid, vol. II, Valladolid, 1930, pp. 188-189.

74 Ángel FERNÁNDEZ COLlado, Gregorio XIII y Felipe II en la nunciatura de Felipe Sega (1577-1581), Roma, 1998, p. 156.

75 Domingo de Ulloa era hijo natural de Rodrigo de Ulloa, Marqués de la Mota. Había profesado en el convento de la Peña de Francia, pero fue colegial de San Ildefonso de Toro (1557), «ocupó las lecturas y cátedra de Artes y Teología de aquella Real casas, hasta recibir el grado de Presentado, que le dio la Provincia en el Capítulo Abulense, 1577. Gobernó los conventos de Palacios, de Toro, de Palencia y de Valladolid; fue Rector de San Gregorio, año 1577; Vicario general de la Provincia de España, Definidor en el Capítulo de Vitoria, 1579, y electo Definidor para el Capítulo general, Puesto que acreditan las prendas de religión, prudencia y letras que le acompañaban, cuando para campease en tantos y tan honrados puestos le buscaba y escogía la Provincia. Aprobólas el gran 
Asimismo, la Orden experimentaba en Castilla una fuerte competencia por parte de los jesuitas, lo que había llevado a varios de sus miembros -en particular a los padres Peredo, Báñez y Avendaño- a precipitarse en un áspero juego de denuncias teológicas desde el púlpito o por escrito, centradas en diversas cuestiones, que iban desde la limpieza de sangre de los miembros de la nueva Orden religiosa, pasando por la Ratio Studiorum de los colegios jesuitas o el poder de la gracia santificante ${ }^{76}$. Un pulso desgastante, que obligó a movilizar contactos en la corte real y también en Roma. Lo cierto es que el temor era justificado, puesto que los padres de la Compañía ganaban rápidamente influencia entre las élites políticas y sociales españolas en menoscabo de las demás órdenes religiosas ${ }^{77}$.

Esto demostraba que, más allá del aparente éxito del programa confesional de Felipe II, las élites hispanas optaban con mayor frecuencia por el modelo educativo propuesto desde Roma y difundido por los jesuitas, quienes apostaban, en el ámbito de la santidad, por modelos imitables para el cristiano. No era éste un fenómeno nuevo, André Vauchez señala que en el siglo XV los reyes poderosos y los obispos dotados de sensibilidad pastoral que habían monopolizado la atención de los creyentes hasta entonces no ofrecían ya, a los ojos de los Papas y de los grandes clérigos de su entorno, los modelos idóneos que había que proponer a la Iglesia universal. Frailes y monjas reemplazaron a los santos antiguos y, en particular, fueron exaltados a los altares algunos reformadores de órdenes religiosas que destacaron por su actividad misional, inquisitorial o profética ${ }^{78}$. A su vez, la

monarca Filipo II, presentándole para Obispo de Nicaragua, en 10 de octubre de 1584. De ella fue promovido a la de Popayán, en 21 de Febrero de 1591, y de este a la de Michoacán, en 11 de agosto de 1596», Gonzalo DE ARriagA, Historia del Colegio... [ver n. 73], pp. 229-230.

76 Antonio ASTRaIN, Historia de la Compañia en la Asistencia de España, t. III, Madrid, 1909, pp. 250327; Doris MORENO, Crear opinión: el dominico Alonso de Avendaño y su predicación antijesuita (15671596), en José Luis Betrán, Bernat HERnANDEs, Doris Moreno (eds.), Identidades y fronteras culturales en el mundo ibérico de la Edad Moderna, Barcelona, 2016, pp. 399-413.

77 Julián Lozano Navarro, La Compañía de Fesús y el poder en la España de los Austrias, Madrid, 2005, pp. 83-118; José MARTíNEZ MilláN, El problema judeo-converso en la Compañía de Jesús, en Chronica Nova, 42 (2016), pp. 19-50.

78 A finales de la Edad Media, los modelos de santidad difieren sensiblemente de los de la época anterior. Hasta el siglo XII, la santidad fue esencialmente reconocida a los obispos y a los monjes. Sin embargo, estos son más raros en el periodo posterior, aun cuando tres cuartos de los santos canonizados o llevados a los altares siguen siendo clérigos. Las órdenes mendicantes dieron, en efecto, numerosos santos con los grandes predicadores que fascinaban a las multitudes, en particular los oradores procedentes de los movimientos de la observancia, ya sea canonizados o no. Los profetas y visionarios que permanecían en la ortodoxia proporcionaron otro batallón de nuevos santos varones y sobre todo de mujeres, que en su mayoría tenía una reputación local de santidad. Véase, André VAUCHEZ, La sainteté en Occident aux derniers siècles du Moyen Age d'après les procès de canonisation et les documents hagiographiques, Roma, 1988, pp. 13 y ss. 
Contrarreforma impulsaría la canonización de santos militantes y heroicos, así como de religiosos fundadores de obras de acogida y practicantes de la caridad cristiana. De hecho, heroicidad y sanación son las palabras que explican las dos visiones sobre la santidad que prevalecieron en el largo tiempo de la Contrarreforma ${ }^{79}$.

Por otro lado, en el ámbito de las hagiografías, el rechazo del culto a los santos por parte de las iglesias reformadas y la crítica específica contra los agregados fabulosos y superfluos en la redacción de las vidas de santos habían promovido la necesidad de introducir una verificación histórica y filológica en los relatos que circulaban bajo el nombre de legendae sanctorum. Si bien el concilio de Trento había confirmado la validez del culto de los santos para la Iglesia romana, el elemento histórico se volvió decisivo para el reconocimiento del culto a los santos. Una tendencia que tuvo impacto, primeramente, en la liturgia, que fue profundamente reformada gracias a la publicación del Breviario Romano de 1568, que jerarquizó las fiestas dedicadas a los santos e inició su depuración. El breviario tridentino representó un intento de regular la recitación del oficio diario por parte de los sacerdotes en todo el mundo católico. El otro libro litúrgico importante para el culto de los santos fue el Martyrologium Romanun: originalmente consistía únicamente en un calendario con anotaciones sobre el santo canonizado, consistente en el día de su aniversario, la indicación del lugar donde eran venerados y el nombre del santo: las coordenadas hagiográficas. Este texto fue publicado en $1584^{80}$.

Por lo tanto, durante la segunda mitad del siglo XVI se verificaba una renovación de los escritos hagiográficos. Y es que sobre todo los teólogos españoles presentes en el concilio de Trento, como el dominico Melchor Cano, tenían conciencia de las lagunas hagiográficas tradicionales y promovieron su renovación. Si bien las primeras tentativas en este sentido fueron infructuosas, en la década de 1570 registraron progresos notables. Entre 1570 y 1575, el cartujo de Colonia Lorenzo Surius publicó una summa en seis volúmenes, acertadamente titulada

79 Eliseo SerRano MarTín, La santidad en la Edad Moderna. Límites, normativa y modelos para la sociedad, en Historia social, 91 (2018), pp. 149-166; Pierre DELOOZ, Pour une étude sociologique de la sainteté canonisée dans l'Eglise catholique, en Archives de sociologie des religions, 13 (1962), pp. 17-43.

80 Ambas obras impulsaron también la reforma de la liturgia de los dominicos, reduciendo el santoral y jerarquizando el breviario de los dominicos. Guillermo NIEVA OCAMPO, En la iglesia con alta y sonora voz: liturgia y devoción entre los Dominicos reformados de Castilla (1480-1550), en Pecia. Le livre et l'écrit, 14 (2012), pp. 57-94. Véase además, Simon DITCHFIELD, Il mondo della riforma e della controriforma, en Anna BENVENUTI (ed.), Storia della santità nel cristianesimo occidentale, Roma, 2005, pp. 261-329; Sofia BoESCH GAJANO, La santità, Roma, 2015, pp. 89-109. 
De probatis sanctorum historiis. Los errores subsistían, pero el espíritu crítico de su autor convirtió a la obra en un texto de referencia durante el próximo medio siglo. Y sobre todo, en 1572, Pedro de Ribadeneira ofreció al público su Vita Ignatii Loyolae S.I. Fundatoris, iniciada tres años antes. El libro reconectaba con un género antiguo, muy popular en el siglo XIV antes de entrar en decadencia, el de la biografía-testimonio. Gracias a este libro, el jesuita llamó la atención de sus contemporáneos sobre el valor pedagógico de los ejemplos de santidad reciente. De este modo, tuvo numerosos émulos: su hermano de hábito Francisco Ribera, biógrafo de Teresa de Ávila, el dominico Luis de Granada o el barnabita Carlo Bascapé, autor de una Vida de Carlos Borromeo, aparecida en $1592^{81}$. En definitiva, los contemporáneos fueron conscientes de la importancia de la historia para la defensa de la ortodoxia litúrgica y devocional, que se materializaría durante el siglo XVII en la actividad de los bolandistas y del equipo de jesuitas dirigido por el cardenal Belarmino.

Hernando del Castillo escribió el primer libro de su historia de la Orden, dedicado a Santo Domingo, en este contexto político, religioso y cultural. De allí que en el mismo prólogo del primer volumen de su obra cite las principales fuentes de las que se valió para su redacción. Junto a la documentación del proceso de canonización, figura el canon de los cronistas del siglo XIII (Sajonia, Franchet, Ferrando, Romans, Orviero y Apoldia); luego vienen las crónicas manuscritas y anónimas que se hallaban en el monasterio de Santo Domingo el Real de Madrid, seguidas de las obras de Bernando Gui, Galvano Fiamma, San Antonino, Leandro Alberti y un largo etcétera, que se completaba con documentación original proveniente de los archivos conventuales españoles ${ }^{82}$.

Ante todo, Castillo considera que Santo Domingo era por sus orígenes un modelo idóneo para los miembros de la nobleza española de tiempos de Felipe II $^{83}:$ «No se ha de tener por fuera de propósito contar su linaje y descendencia:

81 Éric SuIRE, La sainteté française de la réforme catholique (s. XVI'-XVIIr siècles), Burdeos, 2001, p. 25.

82 Hernando Del Castillo, Primera parte de la Historia General de Sancto Domingo y de su Orden de Predicadores, Madrid, 1584, «Prólogo al lector», s/n.

83 Desde el siglo XV, nobleza y ortodoxia cristiana se habían convertido prácticamente en sinónimos, ya que Dios, cuya primera virtud era la nobleza, había creado a los hombres a imagen suya, nobles por lo tanto, y que éstos habían perdido la nobleza con el pecado original. La nobleza, adquirida por el servicio de la res publica, el de las armas o el de las letras, manifestaba pues la vuelta al estado de perfección original, al estado de gracia. Véase, Adeline RUCQUOI, Être noble en Espagne aux XIVe-XVI siècles, en Otto GERHARD Oexle, Werner PARAVICINI (ed.), Nobilitas, Funktion und Representation des Adels in Alteuropa, Gotinga, 1997, pp. 273-298; Mancilla y limpieza: la obsesión por el pecado en Castilla a fines del siglo XV, en Os ùltims fins na cultura ibèrica dos seculos XVXVIII (Porto, 19-21 outubre 1995), Oporto, 1997, pp. 113-135. 
pues sabida la verdad, puede servir de gran ejemplo a los nobles, para seguir las pisadas de quien con nobleza del siglo, juntó tan grande virtud de ánimo» ${ }^{84}$. De hecho, y a pesar del error, la obra de Castillo jugó un papel relevante en la consolidación de la tradición que hacía de Santo Domingo un miembro del linaje Guzmán, cuestión reiterada por los cronistas posteriores ${ }^{85}$.

A pesar del esfuerzo por documentar sus historias, las crónicas eran verdaderos tratados de moral, que promovían la imitación de la conducta de los viris illustribus. No por nada Luis Cabrera de Córdoba, cronista real, definía la historia como «narración por hombre sabio, para enseñar a bien vivir» ${ }^{86}$. De allí que en el siglo XVI no existiese contradicción entre hagiografía e historia, desde el momento en que ambas se encuadraban en un mismo paradigma cultural y concepto de la realidad. Por ello es que fray Hernando señalaba que la vida de los santos y de los frailes de la Orden,

no se pone en historia por solo contarse y escribirse, sino porque es parte de la religión y culto con que debemos venerarlos, saber la vida que hicieron, y tenerla por ejemplo y dechado en nuestras acciones, encaminando las oraciones que les hiciéremos, a que nos alcancen de Dios otro tanto bien como ellos tienen, y nos procuren los medios que para esto son necesarios. De esta manera se ha de ir leyendo la historia de este bienaventurado padre Santo Domingo, mirando desde que tiene uso de razón hasta que muere los pasos que lleva: y venerando su santidad, y al autor de ella, procurar de imitarla, especialmente a los españoles naturales de estos reinos de Castilla, a quien particularmente toca la imitación de tan ilustre castellano ${ }^{87}$.

Particularmente, para Castillo, Santo Domingo era un modelo a imitar porque había sido un fraile observante, es decir, porque había sido piadoso, pobre, austero, puro y compasivo ${ }^{88}$ :

Estando en los conventos era continuo en el coro, primero de todos, así de noche como de día. Mas nunca tuvo celda, ni cama, ni lugar particular ni conocido para dormir, en todo tiempo que le conocieron sus frailes. Porque (como queda

84 Hernando Del Castillo, Primera parte de la Historia de Sancto Domingo... [ver n. 82], f. 6.

$85 \mathrm{Ibid}$. [ver n. 82], f. 6-9. Rucquoi considera que la primera mención del vínculo de Santo Domingo con la familia Guzmán la realizó Pero Tafur a principios del siglo XV. Véase, Adeline RUCQUOI, Dominicus Hispanus... [ver n. 6], pp. 24-38.

86 Luis CABrera de CóRdoba, De historia, para entenderla y escribirla, Madrid, 1611, f. $11 \mathrm{r}$.

87 Hernando Del CaSTILlo, Primera parte de la Historia de Sancto Domingo... [ver n. 82], f. 5 r-v.

88 Acerca de las prácticas ascéticas promovidas por la reforma véase, Guillermo NIEVA OCAMPO, Incorporarse a fesucristo prácticas sacramentales y penitenciales entre los dominicos castellanos en el siglo XVI, en Hispania sacra, 58, 117 (2006), pp. 39-67. 
ya dicho) su ordinaria cama era sobre alguna peaña de los altares, o sentado en el suelo, o en un escaño. Y aun la mejor hora de sueño era la que estaba a la mesa, porque con dos bocados de la miseria que en el refectorio se servía, era acabada su comida, y esperando a los otros se quedaba dormido aquel poco rato, que le bastaba para poder pasarlos muchos de la noche en vela. Arrebatábase en la oración con grandes sentimientos, y algunas veces eran tantas las lágrimas y suspiros y gemidos, que despertaba a los frailes sin advertir a ello. Otras veces quedaba tan elevado y fuera de todo el uso y ejercicio de los sentidos, como si verdaderamente se hubiera ya despedido de ellos. Otras, se levantaba en el aire totalmente y se quedaba el cuerpo suspenso sin llegar a la tierra, con la vehemencia de la oración. Decía misa todos los días: y era tan grande el sentimiento y consideración que en aquel santísimo sacrificio tenía, de la pasión y muerte de Jesucristo nuestro señor que en él se refresca: que le corrían las lágrimas hasta el suelo con una prisa maravillosa, y a veces tal y tan grande, que parecía imposible poder llorar tanto un hombre [...] Tenía una cadena de hierro ceñida al cuerpo, y casi pegada y cosida a las carnes, sin los cilicios ásperos que vestía, según arriba se ha visto. Pero sobre todo espanta lo que todos los testigos que le trataron dicen y depónense de él, conviene a saber, que jamás se acuerdan haberte oído palabra que a su juicio y parecer fuese ociosa, descompuesta, demasiada o airada [...] Amaba mucho la pobreza: y holgávase de traer muy viles pobres hábitos, y así quería que los trajesen sus frailes, y proveía en ello con mucho rigor, y castigaba a los descuidados teniendo por indicio de liviandad en el religioso la curiosidad en el vestido, y por señal de mortificación el paño áspero y de bajo precio, conveniente a pobres, y pobres evangélicos. [...] Y yendo por la calle o por el camino, no alzaba jamás los ojos del suelo, por no divertir la imaginación ni derramarla a cosas e menos sustancia que las que trataba consigo mismo. Para las necesidades espirituales de sus prójimos siempre se hallaba desembarazado. Oía las confesiones de todos los que a él acudían con muy buena voluntad, y lloraba con ellos, y ayudábales a llorar y asentir sus culpas [...] Con todo este rigor que tenía con su persona, era muy blando y amoroso para los súbditos, y dispensaba con ellos fácilmente en algunas cosas, y jamás consigo. Era sobremanera piadoso, discreto en el castigo y reprehensión de los culpados, aguardando siempre tiempo y sazón para castigarlos y reprehenderlos ${ }^{89}$.

De todos modos, es constante el esfuerzo que hace Hernando del Castillo por depurar la «verdad histórica» de relatos fantásticos o falsos, sobre todo en la descripción de la actividad pastoral de Domingo y, particularmente, en la inquisitorial. De hecho, nuestro cronista, que había actuado en numerosas oportunidades como calificador del Santo Oficio, al igual que muchos de sus hermanos

89 Hernando Del Castillo, Primera parte de la Historia de Sancto Domingo... [ver n. 82], f. 140r144r. Véase también ff. 146r-148v. 
de hábito, se preocupó por trascribir algunos documentos que daban cuenta de la práctica judicial del fundador de la Orden en el Languedoc, tomando distancia de la imagen de juez implacable que habían transmitido los frailes observantes a principios del siglo XVI:

Volviendo a Santo Domingo. Este fue su intento, castigar las herejías ejemplarmente y con tantas demostraciones, que asombrasen y espantasen al mundo: $\mathrm{Y}$ los ignorantes, por el rigor de la pena cobrasen aborrecimiento a la culpa. De antes que fuese inquisidor de oficio, sino por sola comisión del legado que andaba en las revoluciones de Tolosa, se halla una sentencia que dio contra un Hereje, a quien recibió a misericordia y le reconcilió en forma, que para nuestros tiempos importa saberse, y dice así [...] En la cual sentencia le condena en sustancia a las cosas y penitencias siguientes. Primeramente que tres domingos arreo sea llevado desde la puerta de la villa hasta la iglesia azotando. Item, Que toda su vida no coma carne, ni huevos, ni leche, ni manteca, salvo los días de Pascua de Resurrección, de Espíritu Santo y de la Natividad de nuestro Señor. Que ayune tres cuaresmas al año, sin comer en ellas pescados, ni huevos, sino yerbas o frutas. Que ayune tres días cada semana toda su vida, y en aquellos días no coma pescado, ni cosa guisada con aceite, ni beba vino sino fuere con dispensación en enfermedad, o en los grandes calores del estío. Que se vista honestamente, así en la hechura del vestido, como en la color. Que traiga dos cruces en los pechos, una sobre la tetilla derecho y otra sobre la izquierda (que es como las aspas de los San Benitos). Que oiga misa cada día, Que las fiestas esté en vísperas. Que rece por las horas canónicas del día por cada una diez veces el Paternoster, y por maitines veinte veces. Que guarde castidad. Que los primeros días de cada mes se presente con esta sentencia ante su cura para que vea como vive, etc. Y que no guardando todo los susodicho (por menos precio) sea tenido por Hereje, perjuro y descomulgado, y apartado de la comunión de los fieles [...] Y del tenor de estas sentencias se deja bien entender el cuidado que este glorioso padre trataba las cosas de la fe y el estilo que los Inquisidores Apostólicos tenían en castigar la Herejía, que no era tan a sobrepeine como algunos querían que hubiese sido y fuese ${ }^{90}$.

Los dos volúmenes escritos por Castillo fueron reeditados en Valladolid en 1612 y con ello se satisfacía, ante todo, la demanda de los conventos españoles.

En definitiva, hay que concluir diciendo que las hagiografías castellanas de Santo Domingo del siglo XVI estuvieron dirigidas a estimular en los frailes el apego a la regular observancia, a partir de la imitación del fundador. Se destacó también la condición noble de Santo Domingo y su actividad pastoral como in-

90 Hernando Del Castillo, Primera parte de la Historia de Sancto Domingo... [ver n. 82], f. 144r146 r. 


\section{GUILLERMO NIEVA OCAMPO}

quisidor, con el fin de señalar el prestigio de una Orden antigua que en aquellos momentos debía competir -a pesar de contar con el monopolio del confesionario regio- con otras más nuevas y dinámicas, como la Compañía de Jesús.

Sánchez Lora ya ha señalado el alto nivel de eficacia alcanzado durante la Edad Moderna española por los ejemplares hagiográficos, justamente por su capacidad mimética. En buena medida, estas obras contribuyeron entre los frailes y monjas a dar sentido a la vida conventual, puesto que proveían de modelos heroicos, sustitutivos de los caballerescos, afanados en la conquista de la virtud probada y de la unión final con Dios ${ }^{91}$. De hecho, es indudable que estas crónicas sirvieron para consolidar la identidad de los dominicos en torno a su fundador y a los principales viris illustribus de la Orden.

\section{REFERENCIAS BIBLIOGRÁFICAS}

ACADEMIA DAS CIÊNCIAS DE LISBOA, Memorias de litteratura portugueza, v. 8, Lisboa, 1812.

Acta Capitolorum Generalium Ordinis Praedicatorum, Benedikt M. REICHERT (ed.), t. IV, 1901.

AlberZoni, Maria Pia, I nuovi Ordini, il IV concilio lateranense e i Mendicanti, en Domenico di Caleruega e la nascita dell'Ordine dei Frati Predicatori. Atti del XLI Convegno storico internazionale. Todi, 10-12 ottobre 2004, Espoleto, 2005, pp. 39-89 [72-84].

AlberZONI, Maria Pia, L'Ordine dei Predicatori e la vita religiosa femmnile fino al generalato di Giordano di Sassonia, en Gianni FESTA, Marco RAININI (ed.), L'Ordine dei Predicatori. I Domenicani: storia, figure e istituzioni (1216-2016), Roma, 2016, pp. 304-324.

Alberzoni, Maria Pia, Le origini dell'Ordine dei Predicatori a Milano, en Gianni Bertuzzi (ed.), L'Origine dell'Ordine dei Predicatori e l'Università di Bologna. Atti del Convegno di Studio (Bologna, 18-20 febbraio 2005), Bolonia, 2006, pp. 194-229.

Alvira Cabrer, Martín, Muret 1213. La batalla decisiva de la Cruzada contra los Cátaros, Barcelona, 2008.

Astrain, Antonio, Historia de la Compañia en la Asistencia de España, t. III, Madrid, 1909.

Barbadillo De la Fuente, Teresa, Vida de santo Domingo de Guzmán del códice de Santo Domingo el Real de Madrid, en Archivo Dominicano, XXXVII (2016), pp. 13-94.

91 El influjo de las hagiografías se amplificó a toda la sociedad al canalizarse su mensaje a través del púlpito, la comedia de santos o las artes plásticas. José Luis SÁNCHEZ LORA, De la epopeya a la bagiografía, la continuidad del modelo beroico, en El diseño de la santidad. La desfiguración de San fuan de la Cruz, Huelva, 2016, pp. 1-46. Véase también, Romeo DE MAIO, L'ideale eroico nei processi di canonizzazione della Controriforma, en Ricerche di storia sociale e religiosa, 2 (1972) pp. 139-160. 
BARONE, Giulia, Il Libellus de initio ordinis fratrum praedicatorum, en Domenico di Caleruega e la nascita dell'Ordine dei Frati Predicatori. Atti del XLI Convegno storico internazionale. Todi, 10-12 ottobre 2004, Espoleto, 2005, pp. 431-440.

Beltrán DE HEREDIA, Vicente, Examen crítico de la bistoriografía dominicana en las Provincias de España y particularmente en Castilla, en Archivum Fratrum Praedicatorum, XXXV (1965), pp. 195-248.

BELTRÁN DE HEREDiA, Vicente, Historia de la reforma de la provincia de España, Roma, 1939.

BIgET, Jean Louis, Saint Dominique, la société du Languedoc, les bons hommes et les vaudois (1206-1217), en Domenico di Caleruega e la nascita dell'Ordine dei Frati Predicatori. Atti del XLI Convegno storico internazionale. Todi, 10-12 ottobre 2004, Espoleto, 2005, pp. 131-179.

Boesch GajanO, Sofia, La santità, Roma, 2015.

CABALlERO EsCAMILLA, Sonia, Los santos dominicos y la propaganda inquisitorial en el convento de Santo Tomás de Avila, en Anuario de estudios medievales, 39, 1 (2009), pp. 357-387

CABRERA DE CóRDOBa, Luis, De historia, para entenderla y escribirla, Madrid, 1611.

CanetTI, Luigi, Giovanni da Vincenza, en Dizzionario Biográfico degli Italiani, LVI, Roma, 2001, pp. 263-267.

CANETTI, Luigi, L'invenzione della memoria. Il culto e l'immagine di Domenico nella storia dei primi frati Predicatori, Roma, 1996.

CARIBOnI, Guido, Domenico e la vita religiosa femenina, en Domenico di Caleruega e la nascita dell'Ordine dei Frati Predicatori. Atti del XLI Convegno storico internazionale. Todi, 10-12 ottobre 2004, Espoleto, 2005, pp. 327-360.

Compendio Historico do Estado na Universidade de Coimbra, Lisboa, 1772.

CREYTENS, Raymond, Les écrivains dominicains dans la chronique d'Albert de Castello, en Archivum Fratrum Praedicatorum 30, 1960, pp. 227-259.

Cronica fratris Ludovici de Valleoleto, en Analecta sacri ordinis fratrum praedicatorum, 20 (1931-2), pp. 727-761, 801-8.

Da Costa Roque, Mário, Livros antigos viseenses. Século XVI, en Beira Alta, 23 (1964).

De ARriaga, Gonzalo, Historia del Colegio de San Gregorio de Valladolid, vol. II, Valladolid, 1930.

DE CAPUA, Raimundo, Opuscula et litterae, Roma, 1895.

DE FAJA, Valeria, Usi politici della profezia gioachimita, en Annali dell'Istituto storio italogermanico in Trento, 25 (1999), pp. 375-400.

DE LA CRUZ, Juan, Coronica de la Orden de Predicadores, de su principio y sucesso basta nuestra edad y de la vida del bien auenturado sancto Domingo su fundador y de los sanctos y varones memorables q en ella florecieron, Lisboa, 1567.

DE LA CRUZ, Juan, Historia de la Iglesia, que llaman eclesiástica y tripartita. Abreviada y trasladada de Latin en Castellano por un religioso de la orden de Santo Domingo, y ahora nuevamente revisada y corregida por el mesmo intérprete, Coimbra, 1554.

DE MAIO, Romeo, L'ideale eroico nei processi di canonizzazione della Controriforma, en Ricerche di storia sociale e religiosa, 2 (1972) pp. 139-160. 


\section{GUILLERMO NIEVA OCAMPO}

Del Castillo, Hernando, Primera parte de la Historia de Sancto Domingo y su Orden de Predicadores, Madrid, 1584.

DElooz, Pierre, Pour une étude sociologique de la sainteté canonisée dans l'Eglise catbolique, en Archives de sociologie des religions, 13 (1962), pp. 17-43.

DITCHFIELD, Simon, Il mondo della riforma e della controriforma, en Anna BENVENUTI (ed.), Storia della santità nel cristianesimo occidentale, Roma, 2005.

EsPonera CERDÁn, Alfonso, Aproximación a la bistoriografía dominicana ibérica desde el Renacimiento hasta la Ilustración (siglos XVI-XVIII), en Archivo Dominicano, 24 (2003), pp. 107-148.

FASOLI, Sara, Tra riforme e nuove fondazioni: l'Osservanza domenicana nel ducato di Milano, en Nuova rivista storica 76 (1992), pp. 417-494.

FERnándeZ Collado, Ángel, Gregorio XIII y Felipe II en la nunciatura de Felipe Sega (1577-1581), Roma, 1998.

FERrandi, Petri, Legenda sancti Dominici, Simon Tugwell op (ed.), Roma, 2015.

FiAmMA, Galvano, Chronica Ordinis praedicatorum ab anno 1170 usque ad 1333 [Chronica parva], Benediktus M. REICHERT OP (ed.), Roma, 1897.

GAGLIARDI, Isabella, Caterina e l'Osservanza domenicana, en Alessandra BARTOLOMEI ROMagnOl, Luciano Cinelli y Pierantonio PIATTI (coord.), Virgo digna Coelo. Caterina e la sua eredità Raccolta di studi in occasione del $550^{\circ}$ anniversario della canonizzazione di santa Caterina da Siena (1461-2011), Roma, 2013, pp. 361-378.

Galmes, Lorenzo y Gómez, Vito T., Santo Domingo de Guzmán. Fuentes para su conocimiento, Madrid, 1987.

GonZÁlez DÁvila, Gil, Teatro eclesiástico de la Iglesia y Ciudad de Osma, Salamanca, 1618.

GuIDonis, Bernardi, Scripta de Sancto Dominico, Simon TugWELl OP (ed.), Roma, 1998.

HujJBERS, Anne, Zealots for souls. Dominican Narratives between Observant Reform and Humanism, c. 1388-1517, Berlin, 2018.

Il papato duecentesco e gli ordini mendicanti. Atti del XXV Convegno internazionale (Assisi, 1314 febbraio 1998), Espoleto, 1998.

KaGAN, Richard, Los cronistas y la Corona. La política de la Historia en España en las edades Media y Moderna, Madrid, 2010, pp. 141-180.

LABRADOR ARROYO, Félix, La casa real portuguesa de Felipe II y Felipe III: la articulación del reino a través de la integración de las elites de poder (1580-1621), v. II, Madrid, 2006 [tesis inédita].

LAPPIN, Anthony, On the family and early years of Saint Dominic of Caleruega, en Archivum Fratrum Praedicatorum, 67 (1997), pp. 5-26.

LAWRENCE, Cliffort H., Medieval Monasticism: Forms of Religious Life in Western Europe in the Middle Ages, New York, 1984 [existe edición en español].

LINDE, Cornelia, Frati Predicatore e predicazione dalle origini alla fine del XVI secolo, en Gianni Festa, Marco RAININI (ed.), L'Ordine dei Predicatori. I Domenicani: storia, figure e istituzioni (1216-2016), Roma, 2016, pp. 257-277. 
Loperráez Corvalán, Juan, Descripción histórica del obispado de Osma, Madrid, 1788. Lozano Navarro, Julián, La Compañía de fesús y el poder en la España de los Austrias, Madrid, 2005.

Mandonnet, Pierre, Saint Dominique. L'idée, l'homme, l'œuvre, Paris, 1938, 2 vols.

MANSELli, Raoul, Eglises et théologies cathares, en Cahiers de Fanjeaux, 3 (1993), pp. 129-176.

MARTíNEZ MilLán, José, El confesionalismo de Felipe II y la Inquisición, en Trocadero: Revista de historia moderna y contemporánea, 6-7 (1994-1995), pp. 103-124.

MarTínez Millán, José, El problema judeo-converso en la Compañia de Jesús, en Chronica Nova, 42 (2016), pp. 19-50.

Martínez Millán, José, Familia Real y grupos políticos. La princesa Doña Fuana de Austria (1535-1573), en José MARTínez Millán (dir.), La corte de Felipe II, Madrid, Alianza, 1994, pp. 73-106.

Medina Escudero, Miguel Ángel, Hernando del Castillo, en Diccionario Biográfico Espanol, http://dbe.rah.es/biografias/18367/hernando-del-castillo

Mira y GómeZ DE MERCADO, María Dolores, Actualización, estudio y edición del Diálogo sobre la necesidad de la oración vocal, obras virtuosas y santas ceremonias de fray fuan de la Cruz (1555), Almería, 2012, pp. 29 y ss.

Mixson, James y Bert Roest (ed.), A Companion to Observant Reform in the Late Middle Ages and Beyond, Leiden, 2015.

Moreno EsPinosa, Gerardo, Don Carlos: el príncipe de la leyenda negra, Madrid, 2006.

MORENO, Doris, Crear opinión: el dominico Alonso de Avendaño y su predicación antijesuita (1567-1596), en José Luis Betrán, Bernat Hernandes, Doris Moreno (eds.), Identidades y fronteras culturales en el mundo ibérico de la Edad Moderna, Barcelona, 2016, pp. 399-413.

NIEVA OCAMPO, Guillermo, En la iglesia con alta y sonora voz: liturgia y devoción entre los Dominicos reformados de Castilla (1480-1550), en Pecia. Le livre et l'écrit, 14 (2012), pp. 57-94.

NIEVA OCAMPO, Guillermo, Frailes revoltosos: corrección y disciplinamiento social de los dominicos de Castilla en la primera mitad del siglo XVI, en Hispania. Revista española de bistoria, 72 (2011), pp. 39-64.

NIEVA OCAMPO, Guillermo, Incorporarse a fesucristo prácticas sacramentales y penitenciales entre los dominicos castellanos en el siglo XVI, en Hispania sacra, 58, 117 (2006), pp. 39-67.

NIEVA OCAMPO, Guillermo, Las reformas de la orden de predicadores en Castilla durante el siglo XV. Movimientos, programas, actores y resultados, en Emilio CALlado ESTELA (ed.), Frailes, santos y devociones. Historias dominicanas en homenaje al Profesor Alfonso Esponera, Valencia, 2020, pp. 203-238.

OlmEDA, Sebastián, Nova chronica ordinis praedicatorum de initio videlicet et successu eius ipsiusque Magistris Generalibus et viris illustribus usque ad annum MM qui et est CCCXXX et ultra ab institutione illius, Manuel CANAL GOMEZ (ed.), Roma, 1936.

PaOlini, Lorenzo, Domenico e gli eretici, en Domenico di Caleruega e la nascita dell'Ordine dei Frati Predicatori. Atti del XLI Convegno storico internazionale. Todi, 10-12 ottobre 2004, Espoleto, 2005, pp. 297-326. 


\section{GUILLERMO NIEVA OCAMPO}

Pennington, Ken, The Church from Pope Innocent III to Pope Gregory IX, en Domenico di Caleruega e la nascita dell'Ordine dei Frati Predicatori. Atti del XLI Convegno storico internazionale. Todi, 10-12 ottobre 2004, Espoleto, 2005, pp. 25-38.

PHILIPPART, Guy, Les légendiers latins et autres manuscrits hagiographiques, Typologie des sources du Moyen Age occidental, Turnhout, 1977.

PolónIA, Amelia, Espaços de intervenção religiosa do Cardeal Infante D. Henrique: Actuação pastoral, reforma monástica e inquisição, en Inês AMORIN y otros (coords.), Em torno dos espaços religiosos monásticos e eclesiásticos: actas do Colóquio de Homenagem a Frei Geraldo Coelho Dias, Oporto, 2005, pp. 17-37 [26].

PRIETO SAYAguÉS, Juan, El acercamiento de la monarquía castellana a la Orden de los Predicadores durante el reinado de Fuan II de Castilla (1406-1454), en En la España Medieval, 39 (2016), pp. 197-224.

RaININI, Marco, Domenico di Caleruega: il primo maestro dell'Ordine, en Gianni FESTA, Marco RAININI (ed.), L'Ordine dei Predicatori. I Domenicani: storia, figure e istituzioni (1216-2016), Roma, 2016, pp. 79-105.

RAININI, Marco, Giovanni da Vicenza, Bologna e l'Ordine dei Predicatori, en Giovanni BERTUZZI (ed.), L'Origine dell'Ordine dei Predicatori e l'Università di Bologna. Atti del Convegno di Studio (Bologna, 18-20 febbraio 2005), Bolonia, 2006, pp. 146-175.

RAININI, Marco, I predicatori dei tempi ultimi. La rielavorazione di un tema escatologico nel costituirsi dell'identità profetica dell'Ordine domenicano, en Cristianesimo nella Storia, 23 (2002), pp. 307-343.

RAININI, Marco, La fondazione e i primi anni del monastero di San Sisto: Ugolino di Ostia e Domenico di Caleruega, en Gabriela ZARRI et alii (ed.), Il velo, la penna e la parola. Le domenicane: storia, instituzioni e scritture. Atti del Convegno intenazionale di studi (Bologna, 11-13 ottobre 2007), Florencia, 2009, pp. 49-70.

REDIGONDA, Abele L., Alberti, Leandro, en Dizionario Biografico degli Italiani, vol. 1, 1960, http://www.treccani.it/enciclopedia/leandro-alberti_(Dizionario-Biografico).

Roest, Bert, Observant Reform in the Late Medieval Religious Orders, en Miri RuBIN y Walter SimOns (ed), The Cambridge History of Christianity, Volume 4: Christianity in Western Europe, c.1100-c.1500, Cambridge, 2009, pp. 446-457.

RomanIs, Humberti, Legendae sancti Dominici, necnon Materia praedicabilis pro festis sancti Dominici et testimonia monora de eodem, adiectis miraculis Rotomagensibus sancti Dominici et Gregorii IX bulla canonizationis eiusdem, Simon TUGWELL OP (ed.), Roma, 2008

RuCQuOI, Adeline, Dominicus Hispanus: ochocientos años de la Orden de Predicadores, Valladolid, Junta de Castilla y León, 2016.

RUCQUOI, Adeline, Etre noble en Espagne aux XIV -XVI siècles, en Otto Gerhard OEXLE, Werner Paravicini (ed.), Nobilitas, Funktion und Representation des Adels in Alteuropa, Gotinga, 1997, pp. 273-298.

RuCQUOI, Adeline, La double vie de l'université de Palencia (c.1180-c.1250), en Studia Gratiana, XXIX (1998), pp. 723-748. 
RuCQuOI, Adeline, Mancilla y limpieza: la obsesión por el pecado en Castilla a fines del siglo XV, en Os ùltims fins na cultura ibèrica dos seculos XV-XVIII (Porto, 19-21 outubre 1995), Oporto, 1997, pp. 113-135.

SÁNCHEZ LORA, José Luis, De la epopeya a la hagiografía, la continuidad del modelo heroico, en El diseño de la santidad. La desfiguración de San fuan de la Cruz, Huelva, 2016, pp. 1-46.

SASTRE VARAS, Lázaro, El obispo Diego de Acebes y el Cabildo de la catedral de Osma. Raíces espirituales de Santo domingo de Guzmán, en Domenico di Caleruega e la nascita dell'Ordine dei Frati Predicatori. Atti del XLI Convegno storico internazionale. Todi, 1012 ottobre 2004, Espoleto, 2005, pp. 106-117.

SAXONIA, Iordani, Libellus de principiis Ordinis Praedicatorum, Heribert Christian SCHEEBEN (ed.), Roma, 1935.

SERRANO MARTÍN, Eliseo, La santidad en la Edad Moderna. Limites, normativa y modelos para la sociedad, en Historia social, 91 (2018), pp. 149-166.

SUIRE, Éric, La sainteté française de la réforme catbolique (s. XVIT-XVIII siècles), Burdeos, 2001.

TALlON, Anne, Le procès en canonisation de Saint Dominique et sa postérité dans la littérature dominicaine, en Domenico di Caleruega e la nascita dell'Ordine dei Frati Predicatori. Atti del XLI Convegno storico internazionale. Todi, 10-12 ottobre 2004, Espoleto, 2005, pp. 491-510.

TugWell, Simon, Notes on the life of St. Dominic, en Archivum Fratrum Praedicatorum, 65 (1995), pp. 5-169; 66 (1996), pp. 56-141; 67 (1997), pp. 27-59; 68 (1998), 5-116; 73 (2003), pp. 5-141.

UrbevetanI, Constantini, Legenda sancti Dominici, Mathias C. Scheeben (ed.), Roma, 1935.

Van Engen, John, From Canons to Preachers: A Revolution in Medieval Governance, en Domenico di Caleruega e la nascita dell'Ordine dei Frati Predicatori. Atti del XLI Convegno storico internazionale. Todi, 10-12 ottobre 2004, Espoleto, 2005, pp. 261-295.

VAUCHEZ, André, La sainteté en Occident aux derniers siècles du Moyen Age d'après les procès de canonisation et les documents hagiographiques, Roma, 1988.

VAUCHEZ, André, Une campagne de pacification en Lombardie autour de 1233. L'action politique des Ordres Mendiants d'après la réforme des statuts communaux et les accords de paix, en Mélanges d'archéologie et d'bistoire, 78 (1966), pp. 503-549.

ViCaIRE, Hubert-Marie, Historia de Santo Domingo, Madrid, 2003 [primera edición en francés: 1982].

ZARRI, Gabriella, Ecclesiastical Institutions and Religious Life in the Observant Century, en James MiXsOn y Bert Roest (ed.), A Companion to Observant Reform in the Late Middle Ages and Beyond, Leiden y Boston, 2015, pp. 23-59. 
